\title{
Stability and function of regulatory $T$ cells expressing the transcription factor T-bet
}

\author{
Andrew G. Levine ${ }^{1}$, Alejandra Medoza ${ }^{1}$, Saskia Hemmers ${ }^{1}$, Bruno Moltedo ${ }^{1}$, Rachel E. \\ Niec $^{1}$, Michail Schizas ${ }^{1}$, Beatrice E. Hoyos ${ }^{1}$, Ekaterina V. Putintseva ${ }^{3}$, Ashutosh Chaudhry ${ }^{1}$, \\ Stanislav Dikiy ${ }^{1}$, Sho Fujisawa ${ }^{2}$, Dmitriy M. Chudakov ${ }^{3,4}$, Piper M. Treuting ${ }^{5}$, and Alexander \\ Y. Rudensky ${ }^{1}$ \\ ${ }^{1}$ Howard Hughes Medical Institute, Immunology Program, and Ludwig Center \\ ${ }^{2}$ Molecular Cytology Core Facility, Memorial Sloan Kettering Cancer Center, New York, NY 10065, \\ USA \\ ${ }^{3}$ Shemyakin-Ovchinnikov Institute of Bioorganic Chemistry RAS, Miklukho-Maklaya 16/10, \\ Moscow 117997, Russia, and Central European Institute of Technology, Masaryk University, \\ Kamenice 753/5, Brno 62500, Czech Republic \\ ${ }^{4}$ Pirogov Russian National Research Medical University, Ostrovityanova 1, Moscow 117997, \\ Russia \\ ${ }^{5}$ Department of Comparative Medicine, University of Washington School of Medicine, Seattle, WA \\ 98195, USA
}

\section{Abstract}

\begin{abstract}
Adaptive immune responses are tailored to different types of pathogens through differentiation of naïve CD4 $T$ cells into functionally distinct subsets of effector $T$ cells $\left(\mathrm{T}_{\mathrm{H}} 1, \mathrm{~T}_{\mathrm{H}} 2\right.$, and $\left.\mathrm{T}_{\mathrm{H}} 17\right)$ defined by expression of key transcription factors (TFs) ${ }^{1}$. Regulatory $\mathrm{T}$ (Treg) cells comprise a distinct anti-inflammatory lineage specified by the X-linked TF Foxp $3^{2,3}$. Paradoxically, some activated Treg cells express the aforementioned effector CD4 T cell TFs, which have been suggested to endow Treg cells with enhanced suppressive capacity $4,5,6$. Whether expression of these factors in Treg cells-akin to effector T cells-is indicative of heterogeneity of functionally discrete and stable differentiation states, or conversely may be readily reversible, is unknown. Here, we demonstrate that in Treg cells expression of the $\mathrm{T}_{\mathrm{H}} 1$-associated TF T-bet, induced at steady state and following infection, gradually becomes highly stable even under non-permissive conditions. Loss-of-function or elimination of T-bet-expressing Treg cells-but not of T-bet in
\end{abstract}

\footnotetext{
Users may view, print, copy, and download text and data-mine the content in such documents, for the purposes of academic research, subject always to the full Conditions of use: http://www.nature.com/authors/editorial_policies/license.html\#termsReprints and permissions information is available at www.nature.com/reprints.

Correspondence and requests for materials should be addressed to A.Y.R. (rudenska@mskcc.org).

Author contributions: A.G.L. and A.Y.R. conceived the study, designed experiments, and wrote the manuscript. A.G.L generated mice, performed experiments, and analyzed data. A.M. designed and performed immunofluorescence experiments and A.M. and S.F. analyzed the data. S.H. assisted with some experiments. B.M. performed TCR sequencing studies. E.V.P. and D.M.C performed TCR sequencing analysis. A.G.L and R.E.N. analyzed and R.E.N., A.C., and S.D. bred Foxp3 YFP-Cre Tbx $21^{F L / F L}$ mice. M.S. performed RNA-seq data analysis. B.E.H. prepared $\mathrm{Nb}$ larvae. P.M.T. performed histological analyses.

The authors declare no completing financial interests.
} 
Treg cells —resulted in severe $\mathrm{T}_{\mathrm{H}} 1$ autoimmunity. Conversely, following depletion of T-betnegative Treg cells, remaining T-bet ${ }^{+}$cells specifically inhibited $\mathrm{T}_{\mathrm{H}} 1$ and CD8 $\mathrm{T}$ cell activation in agreement with their co-localization with T-bet ${ }^{+}$effector $\mathrm{T}$ cells. These results suggest an essential immunosuppressive function for T-bet ${ }^{+}$Treg cells and indicate that Treg cell functional heterogeneity is a critical feature of immune tolerance.

Whether Treg cells expressing the $\mathrm{T}_{\mathrm{H}} 1$-associated $\mathrm{TF} \mathrm{T}$-bet represent a stable sub-lineage of cells with unique function, or rather a transient activation state, remains unknown. To address this question, we assessed stability of T-bet expression in Treg cells using a novel Tbx21 tdTomato-T2A-CreERT2 knock-in allele combined with the R26Y recombination and Foxp3 $3^{\text {Thy } 1.1}$ reporters. The resulting Tbx $21^{R F P-C r e E R T 2}$ mice showed a range of RFP expression and CreERT2 activity faithfully reflecting endogenous T-bet protein levels in major lymphocyte subsets (Fig. 1a; Extended Data Fig. 1a-b). RFP ${ }^{+}$Treg cells comprised between $30-70 \%$ of CD44hi ${ }^{\text {CD62 }} \mathrm{L}^{\text {lo }}$ effector Treg cells in lymphoid organs and nonlymphoid tissues; interestingly, intestinal Treg cells exhibited prevalent co-expression of Tbet and ROR $\gamma$ t, but not T-bet and GATA3 (Extended Data Fig. 1d-i).

Three weeks post tamoxifen administration we found —in contrast to a previous report ${ }^{7}$ - the vast majority of both YFP-labeled Treg and effector CD4 T cells continued to express RFP (Fig. 1b,c; Extended Data Fig. 1j). The percent $\mathrm{YFP}^{+}$cells expressing RFP was similarly high at three and seven months, although percentages of $\mathrm{YFP}^{+}$cells themselves declined, indicating that continual Treg cell recruitment into the T-bet ${ }^{+}$subset balances out cell turnover over time (Fig. 1b,c; Extended Data Fig. 1j). Indicative of intrinsic stability of Tbet $^{+}$Treg cells typical of a differentiated cell state, treatment of Tbx $21^{R F P-C r e E R T 2}$ mice with tamoxifen 3 wk prior to infection with the helminth Nippostrongylus brasiliensis $(\mathrm{Nb}) \mathrm{did}$ not result in loss of RFP expression among $\mathrm{YFP}^{+}$Treg (or effector CD4) T cells despite robust $\mathrm{T}_{\mathrm{H}} 2$ activation and cytokine production in spleens and lungs of infected mice (Fig. 1d; Extended Data Fig. 3a; data not shown).

The presence of small percentages of $\mathrm{YFP}^{+} \mathrm{RFP}^{-}$cells 3 wk post gavage (Fig. 1b,c) suggested that some Treg cells might have experienced a transient unstable T-bet expression at the time of tamoxifen administration. Such a scenario would reconcile the above result

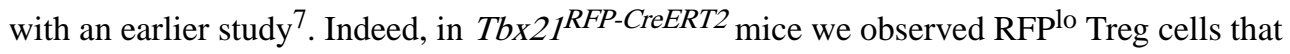
lacked the T-bet-dependent chemokine receptor CXCR3, in addition to RFPhi CXCR3 ${ }^{+}$cells ( Extended Data Fig. 2a). The former exhibited slightly lower CD44 and slightly higher CD62L expression than the latter and RNA-seq analysis suggested CD44 ${ }^{\text {hi }}$ RFP $^{\text {lo }} \mathrm{CXCR}^{-}$ Treg cells to be differentiation intermediates between $\mathrm{CD} 44^{\text {hi }}{ }^{\mathrm{RFP}^{-}}$cells and CD44hi ${ }^{\text {RFPhi }}{ }^{\text {CXCR } 3}{ }^{+}$cells (Extended Data Fig. 2b-d). $~ 40 \%$ of FACS-sorted $\mathrm{RFP}^{\mathrm{lo}} \mathrm{CXCR}^{-}{ }^{-}$(but not RFP ${ }^{\mathrm{C}} \mathrm{CXCR} 3^{+}$) Treg cells lost RFP expression following transfer into lymphoreplete hosts, whereas some became RFP ${ }^{\mathrm{Ci}} \mathrm{CXCR}^{+}$( Extended Data Fig. 2e,f). Notably, populations of $\mathrm{RFP}^{\mathrm{lo}} \mathrm{CXCR}^{-}$and $\mathrm{YFP}^{+} \mathrm{RFP}^{-}$cells were also observed within the CD4 non-Treg cell population (Extended Data Fig. 2a). Thus, the observed instability of a low level of T-bet expression is not unique to Treg cells but is indicative of the gradual process of peripheral $\mathrm{T}$ cell effector differentiation ${ }^{8,9}$. 
In addition to steady state cues, $\mathrm{T}_{\mathrm{H}} 1$-polarizing infection can drive increases in T-bet ${ }^{+}$Treg cells ${ }^{10}$. To determine whether infection expands T-bet ${ }^{+}$Treg cells present at steady state, or rather induces T-bet expression in T-bet ${ }^{-}$cells, we administered tamoxifen to $T b \times 21^{R F P-C r e E R T 2}$ mice $3 \mathrm{wk}$ prior to challenge with the intracellular bacteria Listeria monocytogenes $(\mathrm{Lm})$. Upon $L m$ challenge, $\mathrm{RFP}^{+}$Treg and effector $\mathrm{CD} 4 \mathrm{~T}$ cell subsets increased markedly; however, $\mathrm{YFP}^{+}$subsets did not (yielding a decreased $\mathrm{YFP}^{+} / \mathrm{RFP}^{+}$ratio.) (Fig. 2a,b; Extended Data Fig. 3b). This pattern was indicative of de novo differentiation of T-bet $^{+}$cells from T-bet ${ }^{-}$Treg precursors in parallel with differentiation of $\mathrm{T}_{\mathrm{H}} 1$ cells. Following transfer, both $\mathrm{CD} 44^{\mathrm{lo}} \mathrm{CD} 62 \mathrm{~L}^{\text {hi }} \mathrm{RFP}^{-}$and $\mathrm{CD} 44^{\mathrm{hi}} \mathrm{RFP}^{-}$Treg cells upregulated RFP in response to $L m$ infection ( Extended Data Fig. 3c). Notably, upon Lm infection YFPlabeled T-bet ${ }^{+}$Treg cells did increase expression of T-bet and CXCR3, but not IL-10, an important suppressor molecule ${ }^{11}$, as similar fate mapping experiments in $T b \times 21^{R F P-C r e E R T 2} I L-10^{e G F P / W T}$ mice revealed no increase in IL-10(eGFP) ${ }^{+}$among $\mathrm{YFP}^{+}$ Treg cells even as bulk $\mathrm{RFP}^{+} \mathrm{eGFP}^{+}$cells increased $\sim 3$-fold (Extended Data Fig. 3d-g). Similar results were obtained during LCMV infection (data not shown).

We next assessed the persistence and recall response of $L m$-induced T-bet ${ }^{+}$Treg cells. To preferentially label infection-induced T-bet ${ }^{+}$cells, tamoxifen was administered at the peak of the primary $L m$ response (d7 and 9). Mice were assessed $8 \mathrm{wk}$ later, at which time the percent of splenic and liver Treg cells that were $\mathrm{RFP}^{+}$had returned to roughly pre-infection levels (Fig 2c,d). Given the turnover rate of T-bet ${ }^{+}$cells (Fig. 1c) we reasoned that by d60 post-infection $\mathrm{YFP}^{+}$cells would be relatively enriched for infection-induced Treg cells compared to the bulk $\mathrm{RFP}^{+}$cell pool. Reinfection increased bulk $\mathrm{RFP}^{+}$Treg and effector CD4 T cells and even more prominently increased the corresponding cell subsets tagged with YFP (Fig. 2d; Extended Data Fig. 3h-j). On day 65 following primary infection, >90\% of $\mathrm{YFP}^{+}$Treg cells continued to express T-bet as they did in uninfected controls (Fig. 2e). Furthermore, mice infected with $L m$ that were administered tamoxifen on d37 and 39 following resolution of the primary response and re-infected on $\mathrm{d} 60$ exhibited a parallel increase in bulk $\mathrm{RFP}^{+}$and $\mathrm{YFP}^{+}$Treg cell subsets on $\mathrm{d} 65$, suggesting cells that acquired Tbet expression during primary infection remained T-bet ${ }^{+}$and expanded upon reinfection (Fig. 2f). Together, these studies demonstrate that bacterial infection caused de novo differentiation of T-bet ${ }^{-}$Treg cells into stable T-bet ${ }^{+}$cells uniquely suited for reactivation under conditions that drove their initial acquisition of T-bet.

Although the stability of T-bet ${ }^{+}$Treg cells suggested a particular function presumably imparted by T-bet itself, we found that 12 wk-old Foxp $3^{Y F P-C r e} T b \times 21^{F L / F L}$ mice were clinically indistinguishable from littermate controls, consistent with previous studies ${ }^{7,12,13}$. Foxp $3^{Y F P-C r e} T b \times 21^{F L / F L}$ mice did exhibit mild $\mathrm{T}_{\mathrm{H}} 1$ (but not $\mathrm{CD} 8 \mathrm{~T}$ cell) activation, indicating that T-bet expression in Treg cells moderately potentiated suppression of $\mathrm{T}_{\mathrm{H}} 1$ autoimmunity (Extended Data Fig. 4a). We considered the possibility that T-bet deficiency might not fully impair the function of T-bet ${ }^{+}$Treg cells. Since Treg cell suppressor function requires continuous expression of the Foxp 3 gene $^{14}$ we ablated Foxp3 in T-bet ${ }^{+}$Treg cells using a novel Tbx21tdomato-T2A-Cre allele (Extended Data Fig. 5a). Loss of Foxp3 expression in T-bet ${ }^{+}$Treg cells in 8 wk-old $T b \times 21^{R F P-C r e} F o x p 3^{F L}$ mice resulted in deceased weight gain, lymphadenopathy, $\mathrm{T}$ cell activation, and marked immune infiltration in the 
lung; with age, loss of hair pigmentation and rectal prolapse were evident (Fig. 3a-d; Extended Data Fig. 5).

Indicative of $\mathrm{T}_{\mathrm{H}}$ 1-type inflammation, the majority of expanded effector CD4 and CD8 $\mathrm{T}$ cells in $\mathrm{Tb} \times 21^{R F P-C r e} \mathrm{Foxp} 3^{F L}$ mice expressed RFP (Fig. 3e-g; Extended Data Fig. 5). Additionally, IFN $\gamma$ and IL-2 but neither IL-4 nor IL-17 production by T cells were increased compared to controls (Fig. 3g,h; Extended Data Fig. 5). Antibiotic treatment did not mitigate autoimmunity in $T b \times 21^{R F P-C r e} F o x p 3^{F L}$ mice, excluding microbial antigens as the drivers of $\mathrm{T}_{\mathrm{H}} 1$ inflammation (Fig. 3b; data not shown). We considered whether induction of a robust non- $\mathrm{T}_{\mathrm{H}} 1$ immune response in $T b \times 21^{R F P-C r e} F o x p 3^{F L}$ mice might reveal potential function for T-bet ${ }^{+}$Treg cells in its control. However, the $\mathrm{T}_{\mathrm{H}} 2$ response to $N b$ infection was not increased in $T b \times 21^{R F P-C r e} F o x p 3^{F L}$ compared to control mice, in contrast to the exacerbated $\mathrm{T}_{\mathrm{H}} 2$ response observed upon pan-Treg cell depletion during helminth infection (Extended Data Fig. 6) ${ }^{15,16}$. Importantly, while CXCR3 ${ }^{+}$Treg cells were significantly depleted neither total nor effector Treg cell numbers were diminished, and analysis of $T b \times 21^{R F P-C r e} R 26 Y$ mice confirmed that a significant proportion of effector Treg cells had not undergone Cremediated recombination (Fig. 3d; Extended Data Fig. 5c,f). These results suggested that immune activation could not be attributed to non-specific loss of effector Treg cells.

Cells likely to represent ex-Treg cells lacking Foxp3 but expressing high CD25, CD39, CTLA4, and GITR levels ${ }^{2,17,18}$ were readily found in male $T b \times 21^{R F P-C r e} F o x p 3^{F L}$ and, to a lesser extent, female $T b \times 21^{R F P-C r e} F o x p 3^{F L / W T}$ mice (Fig. 3e; Extended Data Fig. $5 \mathrm{~g}, \mathrm{~h}$ ). The lack of autoimmunity in $T b \times 21^{R F P-C r e} F O x p 3^{F L / W T}$ females-in which only half of T-bet ${ }^{+}$ Treg cells lose Foxp3 due to $\mathrm{X}$-inactivation-indicated that ex-Treg cells were efficiently controlled by remaining T-bet ${ }^{+}$Treg cells (Fig. 3). Moreover, upon adoptive transfer into T cell-deficient hosts, ex-Treg cells induced no more pathology and expanded less than CD4 effector T cells (Extended Data Fig. 7a-c). These results indicate that ex-Treg cells were unlikely drivers of (although it is possible that they may play some role in) the observed autoimmunity.

To determine whether punctual ablation of T-bet ${ }^{+}$Treg cells would similarly unleash $\mathrm{T}_{\mathrm{H}} 1$ inflammation, we generated bone marrow chimeric mice with a 1:1 mix of either CD45.1 $1^{+}$ Foxp $3^{W T}$ or Foxp $3^{K O}$ with CD $45.2^{+} T b x 21^{R F P-C r e / W T} R 26^{i D T R}$ cells (Fig. 4). Prior to DT treatment, both sets of mixed chimeras were healthy with similar basal levels of $\mathrm{T}$ cell activation (data not shown). DT administration over $2 \mathrm{wk}$ resulted in weight loss, profound $\mathrm{T}$ cell activation, and a selective increase in IFN $\gamma$ production by CD4 and CD8 T cells in Foxp $3^{K O}: T b \times 21^{R F P-C r e / W T} R 26^{i D T R}$ chimeric mice ablated of T-bet ${ }^{+}$Treg cells compared to Foxp $3^{W T}: T b \times 21^{R F P-C r e / W T} R 26^{i D T R}$ controls (Fig. 4). Treg cell percentages in experimental mice were only very modestly decreased (from $13 \pm 0.53$ to $11 \pm 0.82, p=0.022$ ) and, as in Tbx $21^{R F P-C r e} F o x p 3^{F L}$ mice, percentages of CD $44^{\text {hi }}{ }^{\text {CD } 62 L^{\text {lo }}}$ Treg cells were undiminished compared to controls (Fig. 4b,c). This experimental model is not confounded by generation of ex-Treg cells, providing additional evidence that the latter were not the sole drivers of pathology in the absence of T-bet ${ }^{+}$Treg cells. Finally, weight loss was not observed in $T c r b^{K O}: T b \times 21^{R F P-C r e} / W T R 2 \sigma^{i D T R}$ mixed chimeras, in which T-bet ${ }^{+}$Treg and effector T-bet ${ }^{+}$ $\mathrm{TCRa} \beta^{+}$cells were simultaneously ablated, implicating the latter in driving disease (Extended Data Fig. 7d,e). 
RNA-seq analysis revealed that 561 genes, including $T b x 21, C X C R 3, G z m b, E b i 3, F g l 2$, and $I 110$ were more highly expressed in $\mathrm{CD} 44^{\mathrm{hi}} \mathrm{RFP}^{+}$compared to CD44 ${ }^{\mathrm{hi}} \mathrm{RFP}^{-}$Treg cells (Extended Data Fig. 2c). Expression of this gene set was further increased upon loss of Foxp3 in ex-Treg cells, suggesting that Foxp3 opposes the transcriptional signature of T-bet ${ }^{+}$ Treg cells to prevent full $\mathrm{T}_{\mathrm{H}} 1$ differentiation (Extended Data Fig. $4 \mathrm{~b}$ ) ${ }^{10}$. Notably, the $\mathrm{T}_{\mathrm{H}}{ }^{1-}$ associated chemokine receptor CCR5 and adhesion molecule $\beta 1$-integrin (CD29) were expressed in T-bet ${ }^{+}$Treg cells independently of T-bet (Extended Data Fig. 4c,d) indicating that some functional redundancy of homing molecules may in part explain the mild phenotype of Foxp $3^{Y F P-C r e} T b \times 21^{F L / F L}$ mice. Moreover, we found that the TCR repertoires of CD44 ${ }^{\text {hi CXCR3(T-bet) }}{ }^{+}$and CD44 ${ }^{\text {hi CXCR3(T-bet) }}{ }^{-}$Treg subsets in DO11.10 TCR $\beta^{+}$ $\mathrm{Tcra}^{+/}$mice were distinct, suggesting that antigenic specificity of T-bet ${ }^{+}$Treg cells may also contribute to distinct localization and suppressor capacity, as recent studies revealed TCR-dependent spatial proximity of Treg and IL-2 producing self-reactive T cells (Extended Data Fig. 4e $)^{19}$.

Therefore, we sought to determine the relative spatial positioning of T-bet ${ }^{+}$and T-bet ${ }^{-}$Treg and effector $\mathrm{T}$ cells in secondary lymphoid organs of Tbx $21^{R F P-C r e}$ mice.

Immunofluorescence imaging revealed pronounced preferential proximity of CD44 ${ }^{\text {hi }}$ T-bet $^{+}$ vs. CD44 ${ }^{\text {hi }}$ T-bet ${ }^{-}$Treg cells to CD44 ${ }^{\text {hi }}$ T-bet ${ }^{+} \mathrm{T}_{\mathrm{H}} 1$ and CD8 $\mathrm{T}$ cells (Fig. 3i-k; Extended Data Fig. 8a-d). In contrast, CD44 ${ }^{\text {hi }}{ }^{-}$-bet ${ }^{+}$Treg cells were no nearer to T-bet ${ }^{-}$CD4 effectors than were CD44 ${ }^{\text {hi }}$ T-bet ${ }^{-}$Treg cells (Fig. 3j; Extended Data Fig. 8c). Notably, the CD44hiTbet $^{-}$Treg cells remaining in $T b x 21^{R F P-C r e} F o x p 3^{F L}$ mice were no nearer to $\mathrm{T}_{\mathrm{H}} 1$ or $\mathrm{CD} 8 \mathrm{~T}$ cells than were CD $44^{\text {hiRFP }}{ }^{-}$Treg cells in healthy $T b \times 21^{R F P-C r e} F o x p 3^{W T}$ mice (Extended Data Fig. 8e,f). This result suggests that failure of non-T-bet ${ }^{+}$Treg cells to approximate $T_{H} 1$ cells may at least in part account for their inability to suppress $T_{H} 1$ inflammation.

Lastly, to complement T-bet ${ }^{+}$Treg cell 'loss-of-function' experiments we sought to selectively eliminate T-bet ${ }^{-}$Treg cells. We generated a Foxp $3^{\text {fl-DTReGFP }}$ allele by inserting a loxP flanked IRES-DTReGFP DNA sequence into the $3^{\prime}$ UTR of the Foxp 3 gene (Extended Data Fig. 9a) and generated Foxp $3^{f l-D T R e G F P} T b x 21^{R F P-C r e E R T 2}$ mice (Fig. 5a). Following 9 days of DT treatment, Treg cells in tamoxifen-pre-treated (d-5 and -3) mice were present in undiminished percentages and were exclusively T-bet and CXCR3 positive (Fig. 5a-c). Compared to vehicle (oil)-treated mice, tamoxifen-treated Foxp $3^{f l-D T R e G F P} T b \times 21^{R F P-C r e E R T 2}$ mice displayed robustly suppressed CD8 T cell activation and selective suppression of IFN $\gamma$ production by CD4 and CD8 T cells, but unrestrained $\mathrm{T}_{\mathrm{H}} 2$ and $\mathrm{T}_{\mathrm{H}} 17$ cytokine production (Fig. 5d-f). T-bet ${ }^{+}$Treg cells similarly suppressed pre-established $\mathrm{T}_{\mathrm{H}} 1$, but not $\mathrm{T}_{\mathrm{H}} 2$ or $\mathrm{T}_{\mathrm{H}} 17$, activation induced by depletion of Treg cells prior to tamoxifen treatment (Extended Data Fig. 9b-g). Selective $\mathrm{T}_{\mathrm{H}} 1$ suppression was not simply a feature of activated Treg cells rebounding post-depletion, as partial depletion and recovery of Treg cells in Foxp $3^{D T R}$ mice resulted in prominently inhibited $\mathrm{T}_{\mathrm{H}} 2$ responses (Extended Data Fig. 9h-1; Extended Data Fig. 10).

Our studies suggest that T-bet expression in Treg cells denotes a differentiated cell state with unique T-bet-dependent and -independent gene expression and TCR specificity, capable of driving potent immunosuppression limited to circumstances of $\mathrm{T}_{\mathrm{H}} 1$ and CD8 $\mathrm{T}$ cell activation. It is possible that GATA3- and ROR $\gamma \mathrm{t}$-expressing Treg cells may play analogous 
roles in suppression of $\mathrm{T}_{\mathrm{H}} 2$ and $\mathrm{T}_{\mathrm{H}} 17$ responses. Such division of anti-inflammatory labor amongst Treg cells, arising at steady state and during infection, may enable focused regulation of specific $\mathrm{T}_{\mathrm{H}}$ responses without incurring undesired bystander suppression.

\section{Experimental Procedures}

\section{Animals}

Tbx21tdTomato-T2A-CreERT2 mice were generated by insertion of a targeting construct into the Tbx21 locus by homologous recombination in embryonic stem cells (ESCs) on the C57BL/6 background; the targeting construct was generated by inserting sequence containing exons 2-5 of the Tbx21 gene from BAC RP23-237M14 (BACPAC Resources Center) into a plasmid backbone containing a PGK promoter driving expression of diphtheria toxin A subunit (DTA) followed by BGHpA sequence (modified PL452 plasmid). A Sall restriction enzyme site was simultaneously engineered into the $T b \times 213^{\prime}$ UTR between the stop codon and the polyadenylation site. The Clontech Infusion HD Cloning system was used to generate in the pUC19 plasmid backbone sequence containing (in order from $5^{\prime}$ to $3^{\prime}$ ) encephalomyocarditis virus IRES; tandem dimer (td) Tomato; T2A self-cleaving peptide from Thoseaasigna virus; Cre recombinase fused to the estrogen receptor ligand binding domain (ER); followed by a frt site-flanked PGK-Neomycin resistance gene (NEO)-BGHpA cassette. The IRES-tdTomato-T2A-CreERT2-frt-NEO-BGHpA-frt sequence was PCRamplified and inserted into the SalI site in the Tbx213'UTR in the modified PL452 backbone. The resulting plasmid was linearized with the restriction enzyme NotI prior to electroporation into ESCs. Tbx21tdTomato-T2A-Cre mice were generated similarly, with Cre recombinase containing a nuclear localization sequence replacing the CreERT2 sequence. Tbx21 tdTomato-T2A-CreERT2 and Tbx21tdTomato-T2A-Cre mice were bred to FLPeR mice to excise the NEO cassette and backcrossed to C57BL/6 mice to remove the FLPeR allele.

Foxp $3^{\text {fl-DTReGFP }}$ mice were similarly generated by insertion of a targeting construct into the Foxp3 locus by homologous recombination in embryonic stem cells (ESCs) on the C57BL/6 background; the targeting construct was generated by inserting sequence containing exons 8-13 of the Foxp3 gene from a 30.8-kb cosmid containing the complete Foxp3 gene into the plasmid backbone containing a PGK promoter driving expression of diphtheria toxin A subunit (DTA) followed by BGHpA sequence (modified PL452 plasmid). The Clontech Infusion HD Cloning system was used to generate in the pUC19 plasmid backbone sequence containing (in order from $5^{\prime}$ to $3^{\prime}$ ) a loxP site; encephalomyocarditis virus IRES; Diptheria toxin receptor (DTR) enhanced green fluorescent protein (eGFP) fusion protein; a triple SV40 polyA (STOP); a second loxP site; encephalomyocarditis virus IRES; Thy1.1; followed by a frt site-flanked PGK-Neomycin resistance gene (NEO)-BGHpA cassette. The loxP-IRES-DTReGFP-STOP-loxP-IRES-Thy1.1-frt-NEO-BGHpA-frt sequence was PCRamplified and inserted into the BaeI site in the Foxp3 3' UTR in the modified PL452 backbone. The resulting plasmid was linearized with the restriction enzyme NotI prior to electroporation into ESCs. Foxp $3^{\text {fl-DTReGFP }}$ mice were bred to FLPeR mice to excise the NEO cassette and backcrossed to C57BL/6 mice to remove the FLPeR allele.

Foxp3 $3^{\text {Thy1.1 }}$, R26Y, Foxp $3^{F L}$, Foxp $3^{K O}$, Rorc ${ }^{G F P}$, Foxp3 $3^{Y F P-C r e}, I L-10^{e G F P}$, and Tbx $21^{F L}$ mice have been previously described ${ }^{2,20,21,22,23,24,25} \cdot C D 45.1, R 26^{i D T R}$, and $T c r b^{K O}$ 
mice were purchased from Jackson Laboratories ${ }^{26}$. Foxp $3^{T h y 1.1} T b x 21{ }^{C r e E R T 2} R 26 Y$ (called $T b \times 21^{C r e E R T 2}$ mice in the text) mice are homozygous at each locus. Tbx $21^{R F P-C r e} F o x p 3^{W T}$, $T b \times 21^{R F P-C r e} F o x p 3^{F L}, T b \times 21^{R F P-C r e} F o x p 3^{W T}, T b \times 21^{R F P-C r e} F o x p 3^{W T W T}$, and $T b \times 21^{R F P-C r e} F o x p 3^{W T / F L}$ mice described in the text are homozygous for the $T b x 21$ knockin allele. Foxp $3^{f-D T R e G F P} T b \times 21^{R F P-C r e E R T 2}$ mice described in the text are homozygous at each locus. Generation and treatments of mice were performed under protocol 08-10-023 approved by the Sloan Kettering Institute (SKI) Institutional Animal Care and Use Committee. All mouse strains were maintained in the SKI animal facility in specific pathogen free (SPF) conditions in accordance with institutional guidelines and ethical regulations.

For tamoxifen administration, $40 \mathrm{mg}$ tamoxifen dissolved in $100 \mu \mathrm{L}$ olive oil (SigmaAldrich) were sonicated $4 \times 30$ seconds in a Bioruptor Twin (Diagenode). Mice were orally gavaged with $200 \mu$ tamoxifen emulsion per treatment. For diphtheria toxin (DT) injections, DT (Sigma-Aldrich) was dissolved in PBS and $200 \mu$ of indicated doses $(1 \mu \mathrm{g} / \mathrm{mouse}$ unless otherwise indicated) were injected i.p per mouse. For antibiotic treatment, mice were weaned onto filtered antibiotic-treated water containing ampicillin, kanamycin, vancomycin, and metronidazole $(0.1 \% \mathrm{w} / \mathrm{v}$ each.)

All mice analyzed were sex and aged matched ( $8-12 \mathrm{wk}$ old) with the exception of some

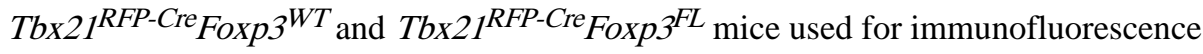
imaging that were up to 10 months of age (results were similar to in $8-12$ wk old mice).

\section{Isolation of cells}

For analysis of YFP-labeled CD4 T cells in Tbx21 RFP-CreERT2 mice, CD4 T cells in spleens and lymph nodes were enriched using the Dynabeads CD4 Positive Isolation Kit (Invitrogen). To isolate lymphocytes from tissues, mice were euthanized and immediately perfused with $20 \mathrm{~mL}$ PBS. Small and large intestines were removed, flushed with PBS and Peyer's patches were removed. $0.5 \mathrm{~cm}$-long fragments of intestines were washed in PBS and incubated in PBS supplemented with 5\% fetal calf serum, $1 \%$ L-glutamine, $1 \%$ penicillinstreptomycin, $10 \mathrm{mM}$ HEPES, $1 \mathrm{mM}$ dithiothreitol, and $1 \mathrm{mM}$ EDTA for 15 minutes. Samples were washed and incubated in digest solution (RPMI supplemented with 5\% fetal calf serum, $1 \% \mathrm{~L}$-glutamine, $1 \%$ penicillin-streptomycin, $10 \mathrm{mM} \mathrm{HEPES,} 1 \mathrm{mg} / \mathrm{mL}$ collagenase, and $1 \mathrm{U} / \mathrm{mL}$ DNase I) for 10 minutes twice. After filtering through a $100-\mu \mathrm{m}$ strainer, cells were resuspended in 35\% Percoll to eliminate debis. Lymphocytes from livers and lungs were isolated by 50-60 min incubation in digest solution, filtered through 100- $\mu \mathrm{m}$ strainers, and after debris removal in 35\% Percoll, purified by centrifugation $(1000 \times \mathrm{g}, 7.5$ min) over a step-wise $44 \% / 67 \%$ Percoll gradient at room temperature.

\section{Nippostrongylus brasiliensis and Listeria monocytogenes infections}

Nippostrongylus brasiliensis $(\mathrm{Nb})$ was maintained by passage in 9 to 10 week-old male Wistar rats as previously described ${ }^{27}$. Briefly, rats were injected subcutaneously (s.c.) with $7000 \mathrm{~L} 3 \mathrm{Nb}$ and stool was collected on days 6-9 post infection. Fecal pellets were mixed with $5 \times 8$ bone charcoal and incubated on moisten filter paper in Petri dishes at $26^{\circ} \mathrm{C}$ for 7 days. L3 larvae were recovered from the edge of the filter paper and the perimeter of the 
plates and extensively washed with PBS to eliminate contaminants before infection. Mice infections were carried out using a 23G needle at a concentration of $500 \mathrm{~L} 3 \mathrm{Nb}$ in $200 \mu \mathrm{L}$. For Listeria monocytogenes $(\mathrm{Lm})$ infections, frozen stocks were thawed, resuspended in Brain-Heart Infusion media, and grown at $37^{\circ} \mathrm{C}$ to an $\mathrm{OD}_{600}$ of 0.1 . For primary infections, mice were injected via lateral tail vein with $5-10 \times 10^{3}$ colony-forming units (cfu) of $\mathrm{Lm}$ diluted in $200 \mu \mathrm{L}$ PBS. For secondary infection, mice were injected via lateral tail vein with $10^{5} \mathrm{cfu}$ of $L m$ in $200 \mu \mathrm{L}$ PBS.

Treatments of rats were performed under protocol 08-10-023 approved by the Sloan Kettering Institute (SKI) Institutional Animal Care and Use Committee. Rats were maintained in the SKI animal facility in Biosafety Level 2 conditions in accordance with institutional guidelines and ethical regulations.

\section{Cell transfer experiments}

For cell transfer experiments, pooled spleens and lymph nodes were enriched for CD4 T cells using the Dynabeads CD4 Positive Isolation Kit. Cells were FACS-sorted on an Aria II cell sorter (BD Bioscience), washed 3 times in PBS, resuspended in $200 \mu \mathrm{L}$ PBS, and transferred into recipients via retro-orbital injection.

\section{Generation of bone marrow chimeric mice}

$\mathrm{Tcrb}^{-/-} \mathrm{Tcrd}^{-/}$recipient mice were lethally irradiated with $650 \mathrm{~Gy}$. The following day, bone marrow was isolated from femurs of donor mice and depleted of T cells and RBCs via staining with biotinylated anti-Thy 1.2 and anti-Ter119 antibodies followed by magnetic bead negative selection. $5 \times 10^{6}$ total $\mathrm{T}$ cell-depleted bone marrow cells were transferred into recipient mice via retro-orbital injection.

\section{Flow cytometric analysis}

Cells were stained with LIVE/DEAD Fixable Yellow Dead Cell Stain (Molecular Probes) and the following antibodies purchased from eBioscience, BioLegend, BD Biosciences, Tonbo, or obtained from the NIH tetramer core facility: anti-CD4 (RM4-5, Biolegend 100548), anti-CD8a (5H10, BD Biosciences 564297), anti-TCR $\beta$ (H57-597, eBioscience 47-5961-82), PBS-57-loaded mCD1d tetramer (NIH 26181), anti-Thy1.1 (HIS51, eBioscience 17-0900-82), anti-CD44 (IM7, BioLegend 103026), anti-CD62L (MEL-14, eBioscience 25-0621-82), anti-CXCR3 (CXCR3-173, eBioscience 17-1831-173), anti-CD25 (PC61.5, eBioscience 17-0251), anti-CTLA-4 (UC10-4B9, eBioscience 17-1522-82), antiGITR (DTA-1, eBioscience 48-5874-82), anti-CD39 (24-DMS1, eBioscience 25-0391-82), anti-CD11b (M1/70, Tonbo Bioscience 25-01120U100), anti-SiglecF (E50-2440, BD Pharmingen 562681), anti-CCR5 (HM-CCR5(7A4) (eBioscience 12-1951-82) and C34-3448 (BD Biosciences 559921), anti-CD29 (eBioHMb1-1, eBioscience 48-0291-80), anti-Foxp3 (FJK-16s, Tonbo Bioscience 35-5773-U100), anti-T-bet (4B10, BioLegend 644816), anti-ROR $\gamma \mathrm{t}$ (B2D, eBioscience 12-6981-82), anti-Gata-3 (TWAJ, eBioscience 46-9966-41), anti-DsRed (Living Colors® DsRed Polyclonal Antibody, Clontech 632496), anti-IFN $\gamma$ (XMG1.2, eBioscience 48-7311-80), anti-IL-4 (11B11, eBioscience 51-7041-82), anti-IL-17A (17B7, eBioscience 61-7177-82), anti-IL-13 (eBio13A, eBioscience 12-7133-82), anti-IL-5 (BD Pharmingen, 554396), and anti-IL-2 (JES6-5H4, eBioscience 
25-7021-82). Flow cytometric analysis was performed using an LSRII flow cytometer (BD Bioscience) and FlowJo software (Tree Star). Intracellular staining was performed using eBioscience Fixation Permeabilization buffers. For cytokine staining lymphocytes were stimulated with soluble anti-CD3 clone $2 \mathrm{C} 11(5 \mu \mathrm{g} / \mathrm{ml})$ and anti-CD28 clone $37.51(5 \mu \mathrm{g} / \mathrm{ml})$ in the presence of $1 \mu \mathrm{g} / \mathrm{mL}$ brefeldin A for 5 hours at $37^{\circ} \mathrm{C}, 5 \% \mathrm{CO}^{2}$. Unless otherwise stated, CD4 T cells were pre-gated as TCR $\beta^{+} \mathrm{PBS}^{-57-C D 1 d}$ tetramer ${ }^{-}$cells.

\section{RNA-seq analysis}

Pooled spleens and lymph nodes were enriched for CD4 T cells using the Dynabeads CD4 Positive Isolation Kit. CD4 ${ }^{+}$Thy $1.1^{+}$cells were FACS-sorted on an Aria II cell sorter (BD Bioscience) into 4 populations (CD62 $\mathrm{L}^{\text {hi }} \mathrm{CD} 44^{\mathrm{lo}} \mathrm{RFP}^{-}, \mathrm{CD} 44^{\mathrm{hi}} \mathrm{RFP}^{-}$, $\mathrm{CD} 44{ }^{\text {hi }}{ }_{\mathrm{RFP}}{ }^{\mathrm{lo}} \mathrm{CXCR} 3^{-}$, and $\mathrm{CD} 44{ }^{\mathrm{hi}} \mathrm{RFP}^{\mathrm{C}} \mathrm{CXCR}{ }^{+}$cells) and resuspended in Trizol. Three replicates of each cell subset were generated. RNA-sequencing reads were aligned to the reference mouse genome GRCm38 using the Burrows-Wheeler Aligner (BWA) ${ }^{28}$ and local realignment was performed using the Genome Analysis Toolkit (GATK) ${ }^{29}$. For each sample, raw count of reads per gene was measured using R, and DESeq2 R package ${ }^{30}$ was used to perform differential gene expression among different conditions. A cutoff of 0.05 was set on the obtained $p$ values (that were adjusted using Benjamini-Hochberg multiple testing correction) to get the significant genes of each comparison.

\section{TCR sequencing and data analysis}

Briefly, following isolation of $\mathrm{CD} 4^{+} \mathrm{T}$ cells from spleens and lymph nodes of DO11.10 TCR $\beta$ transgenic Tcra ${ }^{+/}$Foxp $3^{\text {DTReGFP }}$ mice using the Dynabeads CD4 Positive Isolation Kit (Invitrogen), CD44 ${ }^{\text {hi }} \mathrm{CXCR}^{-}$and $\mathrm{CD} 44^{\text {hi }}{ }^{\mathrm{CXCR}} 3^{+}$eGFP(Foxp3) ${ }^{+}$Treg and eGFP ${ }^{-}$ effector CD4 T cells were FACS sorted and stored in Trizol. TCR sequencing and data analysis were performed as previously described ${ }^{31}$. Pearson correlation of clonotype frequencies for the shared TCR clones was used for the generation of the dendrogram.

\section{Microscopy}

Confocal imaging was done using standard conditions. In brief, micer were perfused in PLP buffer. Lymph nodes and spleens were excised, fixed for 1 hour at room temperature in $4 \%$ paraformaldehyde, and dehydrated at $4{ }^{\circ} \mathrm{C}$ in sucrose (30\% in PBS). Tissues were snap frozen in OCT compound (Sakura Tissue-Tek). $10 \mu \mathrm{m}$ tissue sections were cut and fixed with Acetone for 20 minutes at $-20^{\circ} \mathrm{C}$, rehydrated in PBS and blocked with $10 \%$ normal donkey serum, in PBS with $0.3 \%$ Triton X-100, followed by over night antibody staining at $4^{\circ} \mathrm{C}$ in a humidified chamber. After antibody staining nuclei were stained with $5 \mu \mathrm{M}$ Draq7 (Abcam) for 20 minutes at room temperature. Sections were imaged in Prolong Diamond mounting media (Life Technologies). All images were acquired using a confocal microscope (LSM880; Carl Zeiss) with a 40X oil immersion objective. Images were processed and analyzed using ImageJ software (version 2.0.0-rc-54/1.51h; National Institutes of Health). Nearest neighboranalysis was performed using MATLAB (version R2016b, MathWorks). 


\section{Code availability}

The colocalization program (ImageJ software, 2.0.0-rc-54/1.51h, National Institutes of Health) used to find cell positions and the MATLAB program (software R2016b,

MathWorks) to calculate nearest cell distance are provided as Supplementary Text.

\section{Statistical analysis}

All statistical analyses (excluding RNA-seq and TCR sequence analyses, described above) were performed using GraphPad Prism 6 software. Differences between individual groups were analyzed for statistical significance using the unpaired or paired two-tailed t-test. *, $p \geq$ 0.05 ; **, $p \geq 0.01$; **, $p \geq 0.001$; ns, not significant. The Kolmogorov-Smirnov test is used to determine the significance between the distributions of signature genes and the rest of expressed genes. One-way ANOVA is used to compare the means of 3 or more samples. No statistical method was used to predetermine sample size. The number of mice used in each experiment to reach statistical significance was determined on the basis of preliminary data. No animals were excluded from the analyses. No methods of randomization were used to allocate animals into experimental groups. No blinding was used. Data met assumptions of statistical methods used and variance was similar between groups that were statistically compared.

\section{Data availability}

The RNA-seq data that support the findings of this study have been deposited in the NIH SRA database with the accession code SRP102941. 


\section{Extended Data}

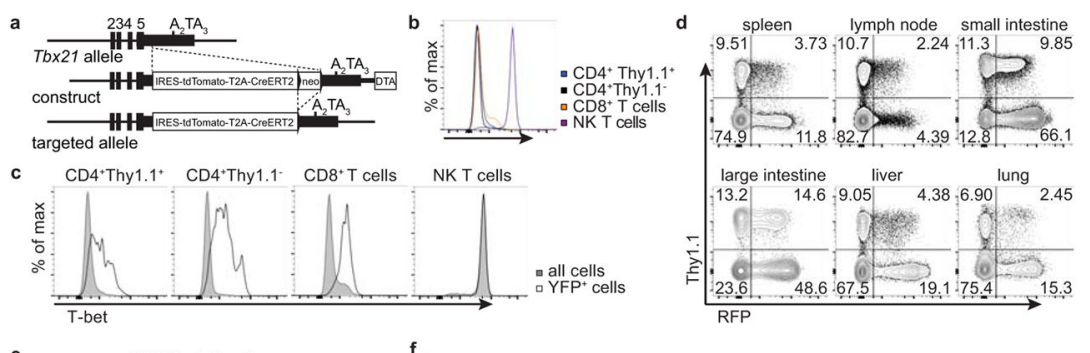

e
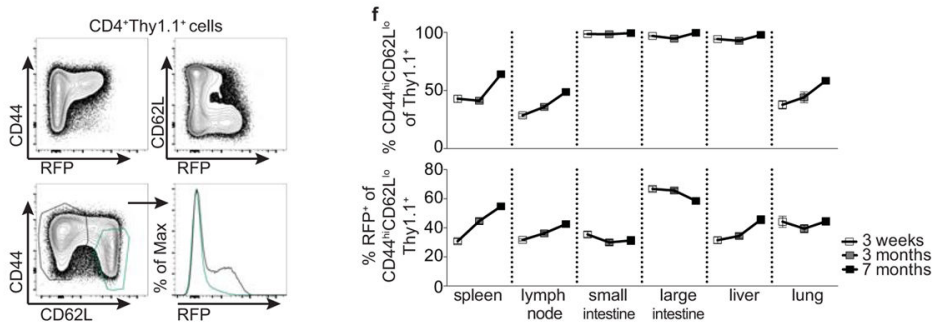

g
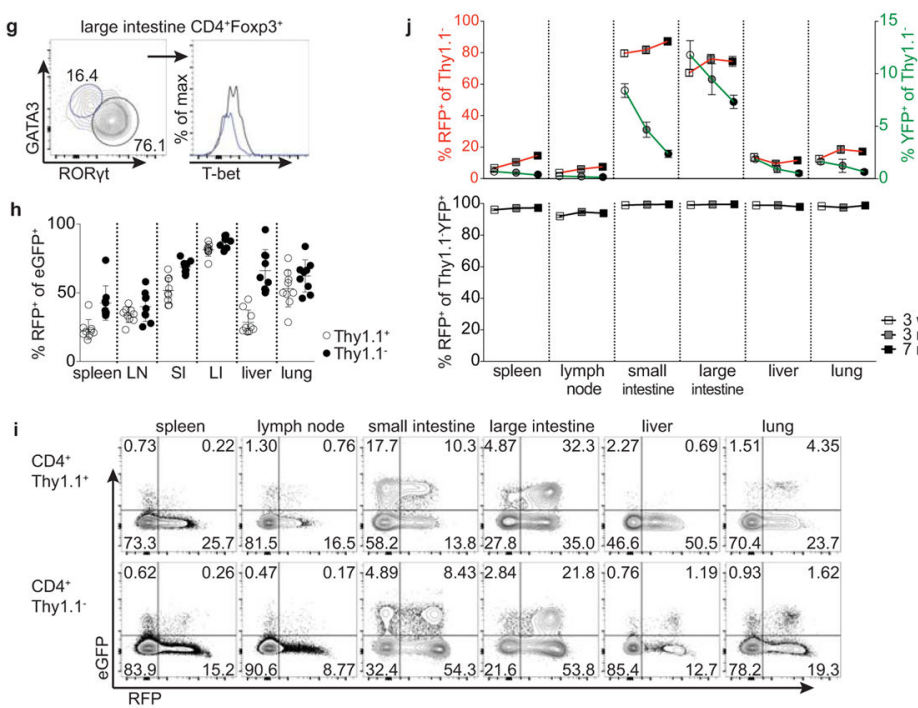

Extended Data Figure 1. Analysis of T-bet ${ }^{+}$cells in Tbx21 ${ }^{R F P-C r e E R T 2}$ reporter mice a, Targeting strategy for the $T b \times 21$ locus. b, T-bet protein levels in immune cells in $T b \times 21^{R F P-C r e E R T 2}$ mice. c, T-bet protein levels in $T b \times 21^{R F P-C r e E R T 2}$ mice gavaged with tamoxifen (tx) on days -2 and 0 and analyzed $3 \mathrm{wk}$ later. Shaded gray and open histograms represent all and $\mathrm{YFP}^{+}$cells, respectively. d, Flow cytometry of RFP expression in Treg and nonTreg CD4 T cells. e, Flow cytometry of splenic Treg cells. f, Percent CD44hi CD62L ${ }^{\text {lo }}$ among Thy $1.1^{+}$(above) and $\mathrm{RFP}^{+}$among CD44hi CD62L ${ }^{\text {lo }}$ Thy $1.1^{+}$(below) cells in $T b \times 21^{R F P-C r e E R T 2}$ three weeks (white squares), three months (gray squares), and seven months (black squares) post tx treatment. g, Flow cytometry of T-bet expression in GATA3 ${ }^{+}$ (blue gate, left, and histogram, right) and ROR $\gamma \mathrm{t}^{+}$(black gate, left, and histogram, right) Treg cells isolated from the large intestine laminia propria. $\mathbf{h}$, Percent $\mathrm{RFP}^{+}$cells among $\mathrm{eGFP}^{+} \mathrm{CD} 4^{+}$Thy $1.1^{+}$(open circles) and Thy $1.1^{-}$(black circles) cells in $T b \times 21^{R F P-C r e E R T 2}$ Rorc $^{G F P / W T}$ mice. LN, lymph node; SI, small intestine; LI, large intestine. i, Flow cytometry of CD4 $\mathrm{T}$ cells in $T b \times 21^{R F P-C r e E R T 2}$ Rorc $G F P / W T$ mice as quantified in (h). 
$\mathbf{j}$, (Above) $\mathrm{RFP}^{+}$(left axis, squares) and $\mathrm{YFP}^{+}$(right axis, circles) effector CD4 T cells; (below) Percent $\mathrm{RFP}^{+}$among $\mathrm{YFP}^{+}$effector CD4 T cells 3 weeks (white symbols), 3 months (gray symbols), and 7 months (black symbols) post tx gavage, as outlined in Fig 1b. Bars, mean \pm s.e.m. All data are representative of $\geq 2$ experiments, $n \geq 4$ mice per group each.

a

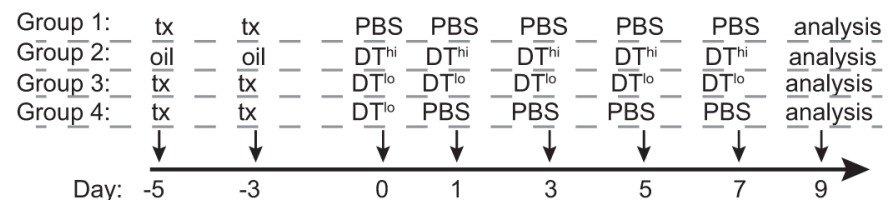

b

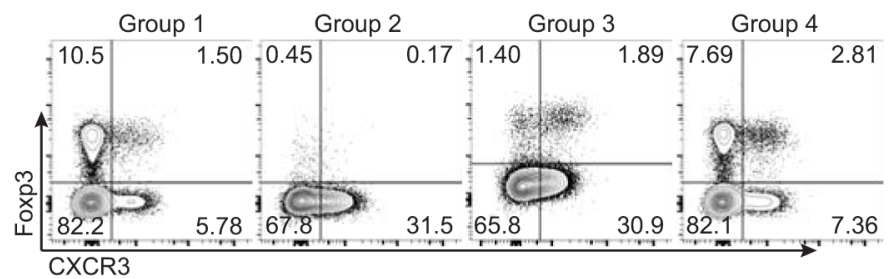

c

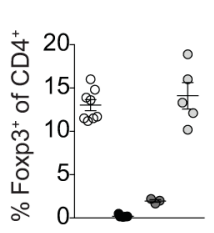

d
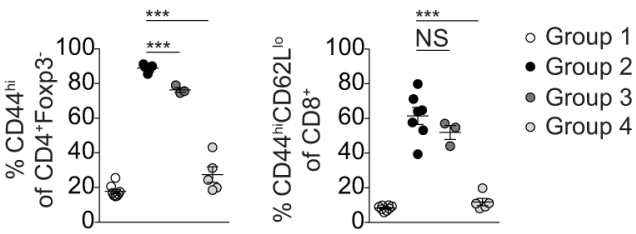

e
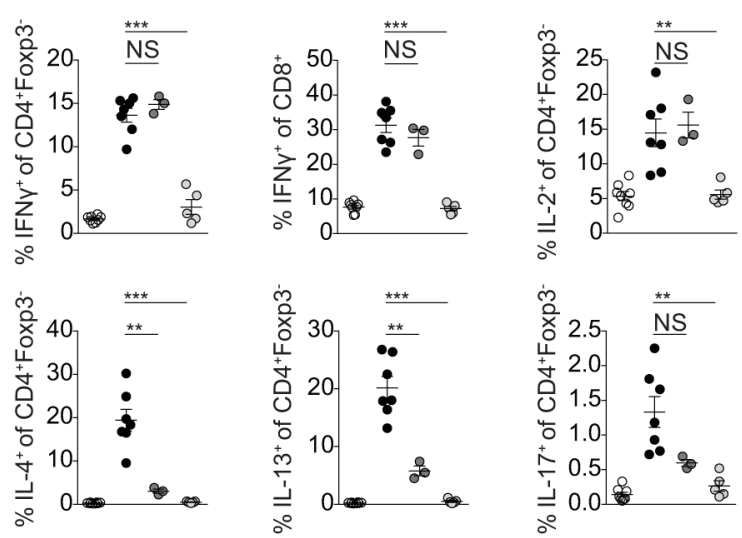

Extended Data Figure 2. T-bet ${ }^{l o}$ cells likely represent transient unstable intermediates in the differentiation of stable T-bet ${ }^{\text {hi }}$ Treg cells

a, Flow cytometry of the indicated cell subsets. b, CD44 and CD62L expression on $\mathrm{RFP}^{-} \mathrm{CXCR}^{-}$(gray shaded histograms, squares), $\mathrm{RFP}^{\text {lo }} \mathrm{CXCR}^{-}$(black histograms, squares), and $\mathrm{RFP}^{\mathrm{hi}} \mathrm{CXCR} 3^{+}$(red histograms, squares) splenic CD4 ${ }^{+}$Thy $1.1^{+}$cells. c, Differential gene expression between CD $44^{\text {hi }}{ }^{R_{F P}}{ }^{-}$and CD $44^{\text {hi }}{ }^{\text {RFPhi }}{ }^{\text {CXCR }}{ }^{+}$Treg cells sorted from pooled spleens and lymph nodes of $T b \times 21^{R F P-C r e E R T 2}$ mice. All genes significantly up (red)- or down-regulated (blue) are indicated. d, Expression of the 288 genes up- ( $\geq 1.5$-fold; left) or 184 genes down-regulated ( $\leq 1.5$-fold; right) in $\mathrm{CD}_{4} 4^{\mathrm{hi}} \mathrm{RFP}^{\mathrm{hi}} \mathrm{CXCR}^{+}{ }^{+}$vs. CD $44^{\text {hi }}{ }^{\mathrm{RFP}}{ }^{-}$cells. Genes with a mean expression value $<15$ were excluded from the analysis. $p$, paired $t$ test; adjustments were made for multiple comparisons. e, CD $44^{\text {lo }} \mathrm{CD}_{22} \mathrm{~L}^{\text {hi }} \mathrm{RFP}^{-}, \mathrm{CD} 44^{\mathrm{hi}} \mathrm{RFP}^{-}, \mathrm{CD}_{4} 4^{\text {hi }} \mathrm{RFP}^{\mathrm{lo}} \mathrm{CXCR}{ }^{-}$, and 
CD $44^{\text {hi }}{ }^{R F P}{ }^{\text {hi }}$ CXCR $3{ }^{\text {hi }} \mathrm{CD} 4{ }^{+}$Thy $1.1^{+}$cells were FACS-sorted and transferred into lymphoreplete hosts and analyzed in pooled spleens and lymph nodes 14 days after transfer. f, Quantification of data in (e) using a two-tailed $t$ test $(* * *$ denotes $p$ values $<0.001)$. All data are representative of $\geq 2$ experiments, $n \geq 2$ mice per group each.

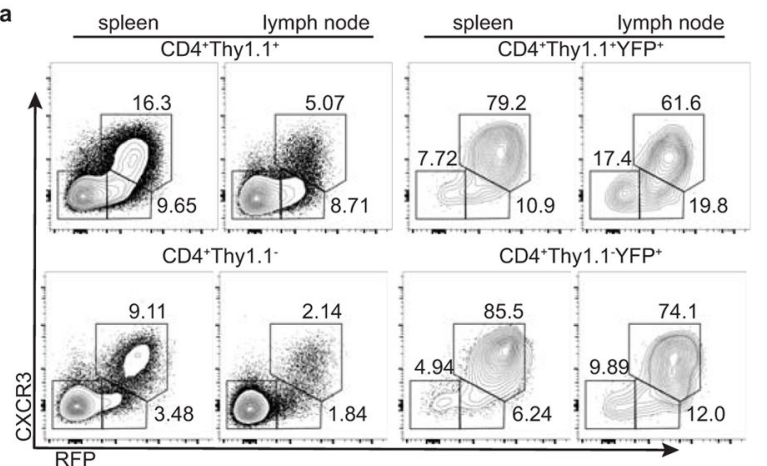

b
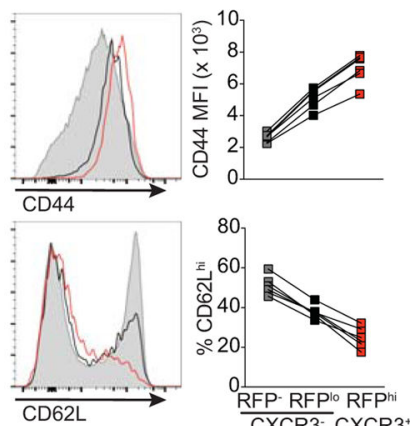

c

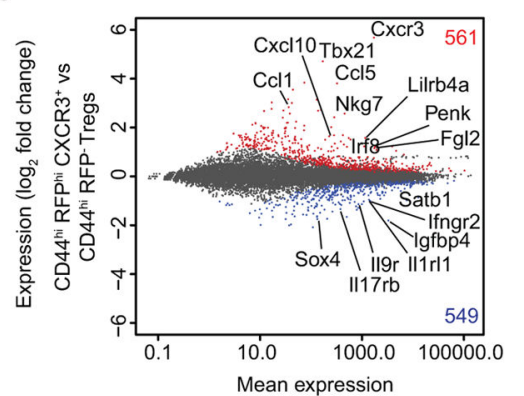

d $\quad p=2.5 \times 10^{-9} p=3.8 \times 10^{-9}$

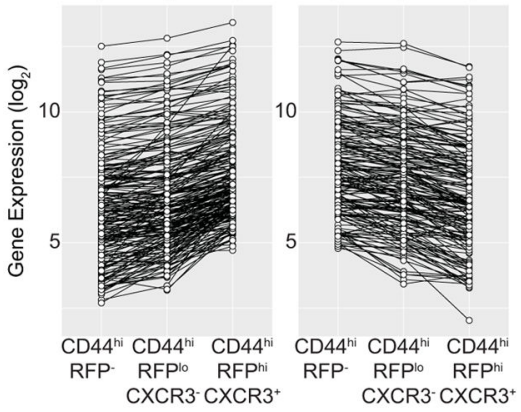

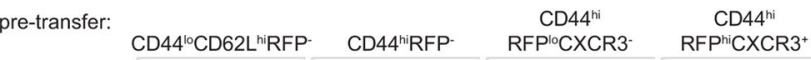
post-transfe

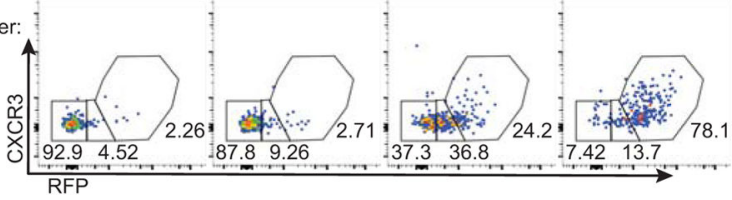

f

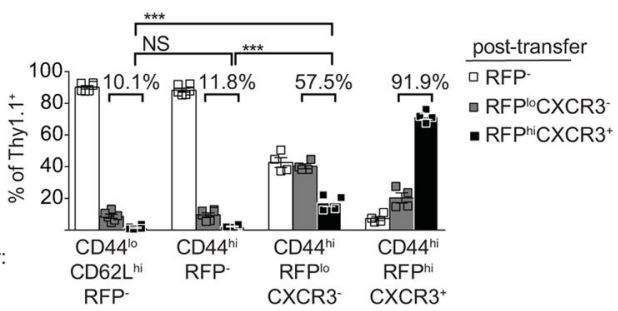

Extended Data Figure 3. Fate mapping T-bet-expressing Treg cells during infectious challenge a, Preferential expansion of CD44 ${ }^{\text {hi }} \mathrm{RFP}^{-}$vs. CD $44^{\text {hi }} \mathrm{RFP}^{+} \mathrm{CD} 4$ effector T cells during Nippostrongylus brasiliensis $(\mathrm{Nb}$ ) infection. Flow cytometry analysis of splenic (above) and lung (below) $\mathrm{CD}^{+}$Thy $1.1^{-}$cells from PBS- (left) and $\mathrm{Nb}$ - (right) challenged mice. b, Flow cytometry of splenic CD4+ ${ }^{+}$Thy $1.1^{+}$(left) and Thy $1.1^{-}$(right) cells of PBS- (above) and $\mathrm{Lm}^{-}$ (below) challenged mice, as indicated in Fig 2a. Numbers indicate percent $\mathrm{RFP}^{+}$(left) and $\mathrm{YFP}^{+}$(right) cells. c, (Above) schematic of experiment. CD44 ${ }^{\mathrm{lo}} \mathrm{CD} 62 \mathrm{~L}^{\mathrm{hi}} \mathrm{RFP}^{-}$, 
CD $44{ }^{\text {hi }}$ RFP $^{-}$, and CD $44^{\text {hi }}{ }_{\text {RFPhi }}$ CXCR $3{ }^{\text {hi }} \mathrm{CD} 4{ }^{+}$Thy $1.1^{+}$cells were FACS-sorted from pooled spleens and lymph nodes of $T b \times 21^{R F P-C r E E R T 2}$ mice and transferred into lymphoreplete hosts one day before PBS or $L m$ challenge. (Below) Flow cytometry of transferred populations (indicated on left) on d9 in spleens of PBS- (left) or Lm- (right) challenged hosts. d, Representative histograms of RFP and CXCR3 expression on total CD4 ${ }^{+}$Thy $1.1^{+}$(shaded histograms) or Th1.1 $1^{+} \mathrm{YFP}^{+}$(open histograms) cells from spleens of PBS- (black) or $L m$ - (red) challenged mice, as indicted in Fig 2a. e-g, eGFP expression in PBS or $L m$ challenged $T b \times 21^{R F P-C r e E R T 2} I L-10^{e G F P}$ mice. e, Schematic of tamoxifen (tx) administration to $T b \times 21^{R F P-C r e E R T 2} I L 10^{e G F P / W T}$ mice for data shown in (f,g). f, Flow cytometry of Treg (above) and $\mathrm{YFP}^{+}$Treg (below) cells in spleens of PBS (left) and $\mathrm{Lm}$ (right) treated mice. g, (Left) percent $\mathrm{RFP}^{-} \mathrm{eGFP}^{+}$and $\mathrm{RFP}^{+} \mathrm{eGFP}^{+}$among Treg cells, as gated in (f, above); (right) percent $\mathrm{eGFP}^{+}$cells among $\mathrm{YFP}^{+}$Treg cells, as gated in (f, below). $\mathbf{h}$, Schematic of $L m$ reinfection in Tbx21 ${ }^{R F P-C r e E R T 2} I L 10^{e} G F P / W T$ mice for data shown in $(\mathbf{i}, \mathbf{j}) ; 1^{\mathrm{o}}$ and $2^{\mathrm{o}}$ indicate primary and secondary challenge, respectively. $\mathbf{i}$, Flow cytometry of cells in Tbx $21^{R F P-C r e E R T 2} I L-10^{e G F P}$ mice on d65, treated as indicated above. $\mathbf{j}$, Percent $\mathrm{RFP}^{-} \mathrm{eGFP}^{+}$and $\mathrm{RFP}^{+} \mathrm{eGFP}^{+}$cells among Thy $1.1^{+}$cells, as gated in (i). All data are representative of $\geq 2$ experiments, $\mathrm{n} \geq 2$ mice per group each. Bars, mean \pm s.e.m. Two-tailed $t$ test (NS - not significant). 
a

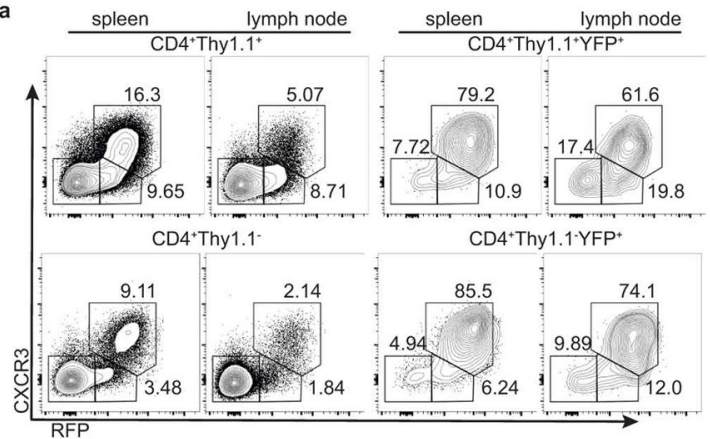

b

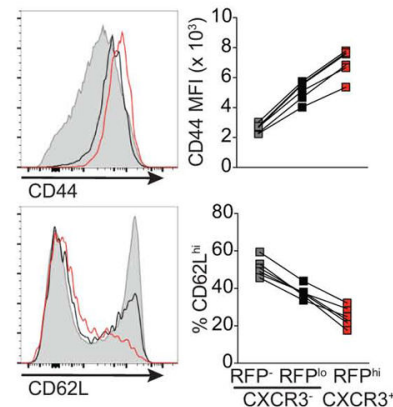

c

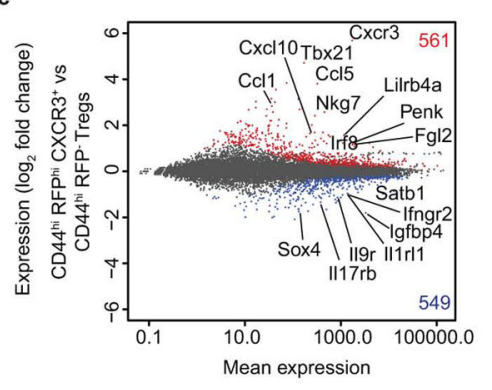

d $\quad p=2 . \underline{5 \times 10^{-9}} \underline{p=3.8 \times 10^{-9} \quad p=3.4 \times 10^{-7}} \underline{p=3.8 \times 10^{-7}}$

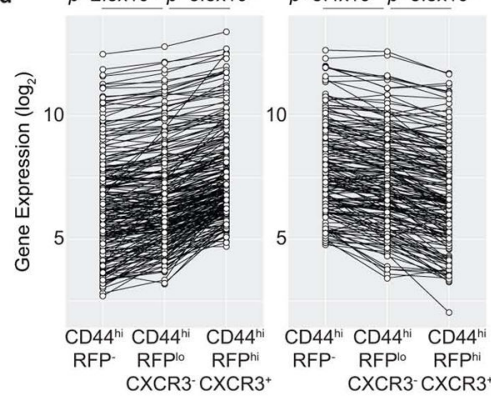

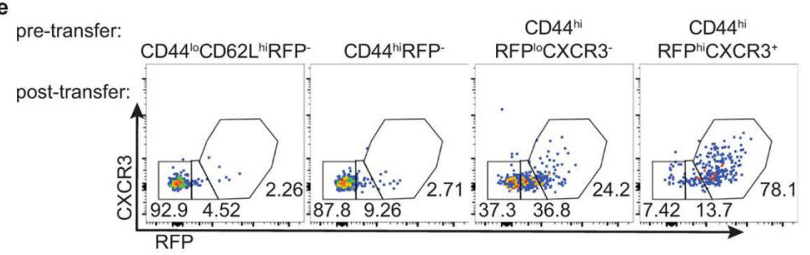

f

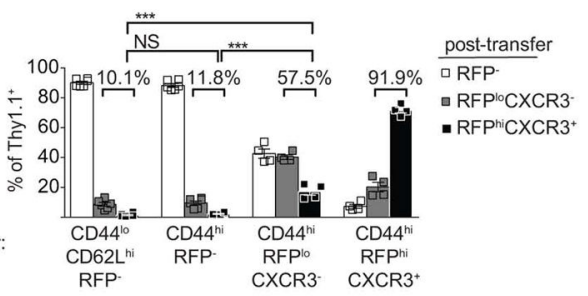

Extended Data Figure 4. Features of T-bet ${ }^{+}$Treg cells

a, T cell activation, CXCR3 expression, and cytokine production in $12 \mathrm{wk}$ old control Foxp3 $3^{Y F P-C r e} T b \times 21^{W T / W T}$ and Foxp3 ${ }^{Y F P-C r e} T b \times 21^{F L / W T}$ (white circles) and experimental Foxp $3^{Y F P-C r e} T b \times 21^{F L / F L}$ (black circles) mice. Bars, mean \pm s.e.m. Two-tailed $t$ test (* denotes $p$ value $<0.05$; NS - not significant). Data is representative of 3 experiments, $\mathrm{n} \geq 7$ mice per group. $\mathbf{b}$, Cumulative distribution function plot of the 561 genes up in Thy $1.1^{+}$ CD44 ${ }^{\text {hi }}{ }_{\text {RFPhi }} \mathrm{CXCR}^{+}{ }^{+}$vs. CD $44^{\text {hi }}{ }^{\mathrm{RFP}}{ }^{-}$cells in $T b \times 21^{R F P-C r e E R T 2}$ mice compared to all genes differentially expressed in $\mathrm{CD} 4{ }^{+} \mathrm{CD} 25^{+}$Treg vs. $\mathrm{CD} 4{ }^{+} \mathrm{CD} 25^{\mathrm{lo}}$ exTreg cells. $\mathrm{P}=0.2 \mathrm{xE}^{-15}$, two-sample Kolmogorov-Smirnov test. c, Expression of CCR5 (above) and $\mathrm{CD} 29$ (below) in CD44 ${ }^{\mathrm{lo}} \mathrm{CD} 62 \mathrm{~L}^{\text {hi }}$ naïve (blue histogram), CD44hi CXCR3 ${ }^{-}$(black histogram) and CD44 ${ }^{\text {hi }} \mathrm{CXCR}^{+}$(red histogram) Treg (left) and CD4 ${ }^{+}$Foxp3 ${ }^{-}$(right) T cells from spleens of Foxp $3^{Y F P-C r e} T b x 21^{W T / W T}$ mice. d, Expression of CXCR3 (left), CCR5 (middle), and CD29 (right), gated on CD4 T cells in spleens of Foxp $3^{Y F P-C r e} T b x 21^{W T / W T}$ and $F o x p 3^{Y F P-C r e} T b x 21^{F L / F L}$ mice. e, Dendrogram represents cluster analysis of TCR 
sequences in $\mathrm{CD}_{4} 4{ }^{\mathrm{hi}} \mathrm{CXCR} 3{ }^{+}$(red symbols) and $\mathrm{CD} 44{ }^{\mathrm{hi}} \mathrm{CXCR}^{-}{ }^{-}$(black symbols) Treg (right) and effector CD4 T (left) cells in spleens (white symbols) and lymph nodes (gray symbols) of DO11.10 TCR $\beta^{+} \mathrm{Tcra}^{+/-}$Foxp3 reporter mice. Sample preparation and statistical analyses are described in the Methods section. Pearson correlation of clonotype frequencies for the shared TCR clones was used for the generation of the dendrogram.

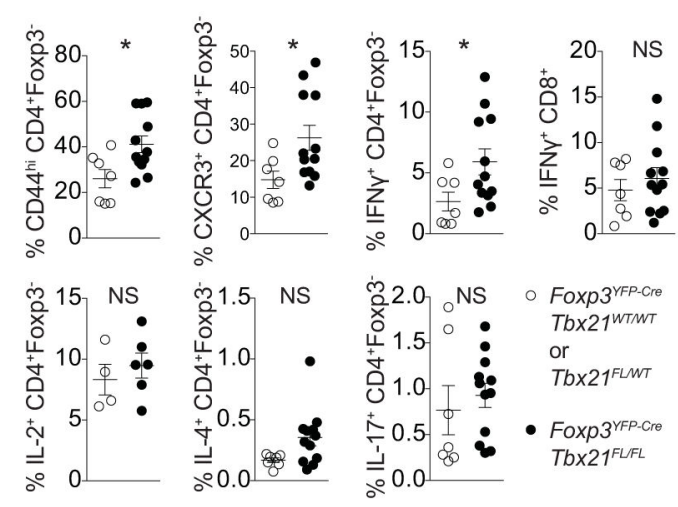

b

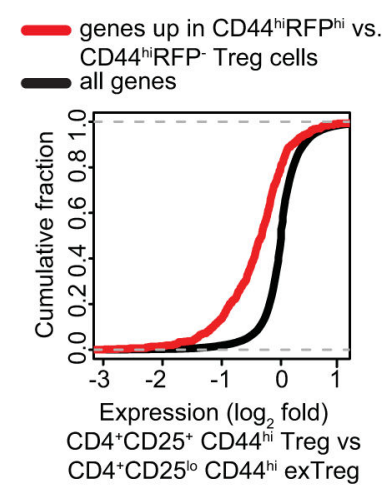

C
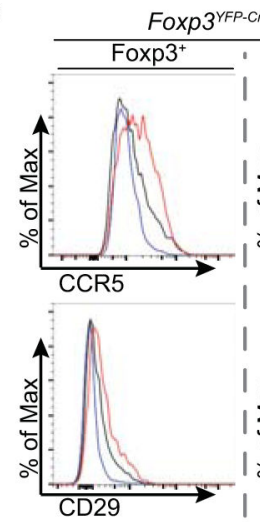

- CD44 ${ }^{10} \mathrm{CD} 62 \mathrm{~L}^{\mathrm{hi}}$

- CD44 ${ }^{\mathrm{hi}} \mathrm{CXCR} 3^{-}$

- CD44 ${ }^{\text {hi }}$ XXR3 $^{+}$ d

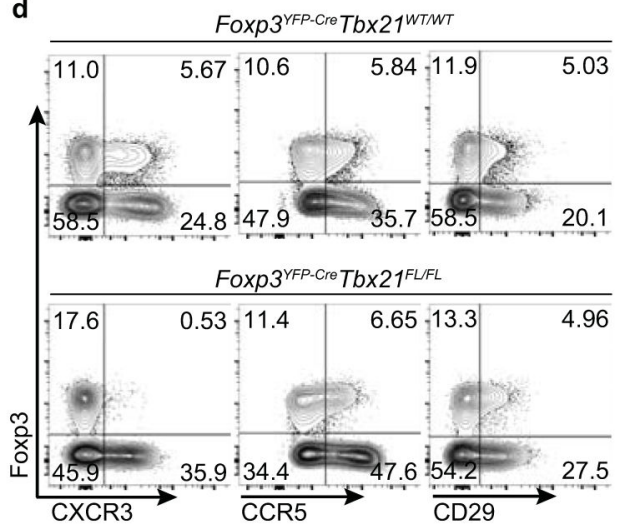

e $\square \mathrm{CXCR}^{+} \square$ spleen

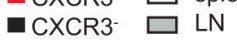

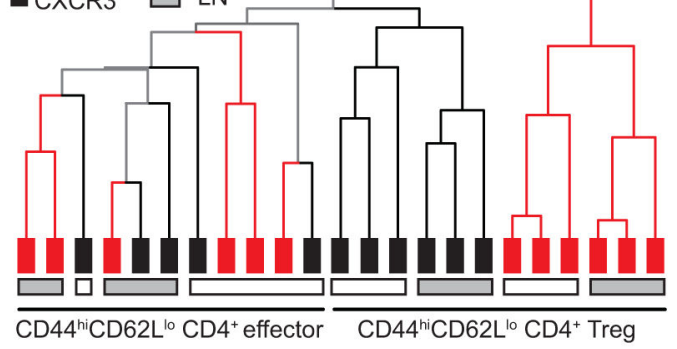

Extended Data Figure 5. Characterization of Tbx21 ${ }^{R F P-C r e} \mathrm{Foxp}^{\mathrm{FL}}$ mice

a, Targeting strategy for the $T b \times 21$ locus (above) and RFP expression in the indicated cell populations in spleens of homozygous $T b x 21^{R F P-C r e}$ mice (below). b. Progressive loss of hair pigmentation in $T b \times 21^{R F P-C r e} F o x p 3^{F L}$ mice. c, (Above) RFP and YFP expression and (below) CD44 and CD62L expression in the indicated splenic cell populations in $T b \times 21^{R F P-C r e} R 26$ Y mice. $\mathbf{d}$, Activation and expansion of $\mathrm{RFP}^{+} \mathrm{T}$ cells in lymph nodes (above) and lungs (below) of the indicated mice. e, Cytokine production by $\mathrm{CD}^{+}{ }^{+} \mathrm{Foxp} 3^{-}$ 
and $\mathrm{CD} 8^{+} \mathrm{T}$ cells in lungs of the indicated mice. $\mathbf{f}$, Characterization of lymph node Treg cells. g, Percentages of ex-Treg cells in spleens, lymph nodes, and lungs. h, (Above) flow cytometry of lymph node CD4 T cells, as quantified in (g); numbers indicate the percent Foxp $3^{-} \mathrm{CD} 25^{+}$; (below), histograms showing expression of Treg cell signature molecules in $\mathrm{CD} 4^{+} \mathrm{Foxp} 3^{-} \mathrm{CD} 25^{+}$cells in lymph nodes of $T b \times 21^{R F P-C r e} F o x p 3^{W T}$ (open gray histogram), $T b \times 21^{R F P-C r e} F o x p 3^{F L}$ (open red histogram), Tbx $21^{R F P-C r e} F o x p 3^{W T / W T}$ (open blue histogram), and $T b \times 21^{R F P-C r e} F o x p 3^{F L / W T}$ (open black histogram) mice. CD $4^{+}$Foxp $3^{+} \mathrm{CD} 25^{+}$cells from a $T b \times 21^{R F P-C r e} F o x p 3^{W T}$ (shaded gray histogram) mouse are shown as a point of reference. Bars, mean \pm s.e.m. Two-tailed $t$ test (***,**, and $*$ denotes $p$ values $<0.001,0.01$, and 0.05 , respectively; NS - not significant). Data represent the combined results from several experiments. 


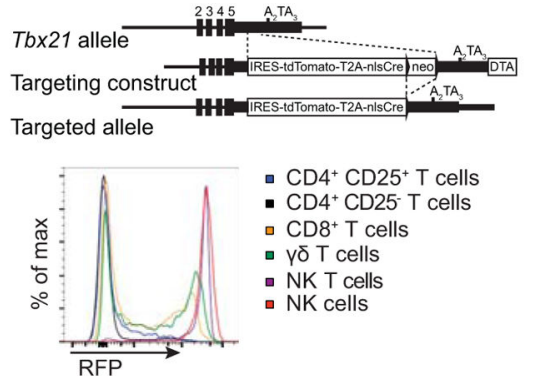

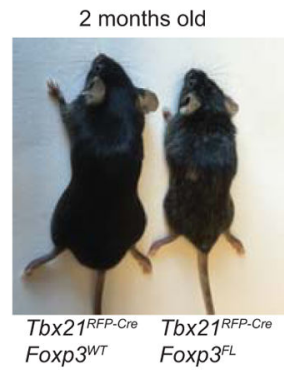

1 year old

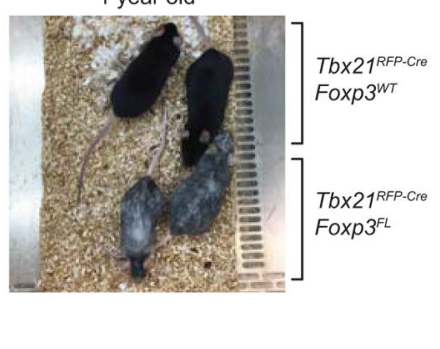

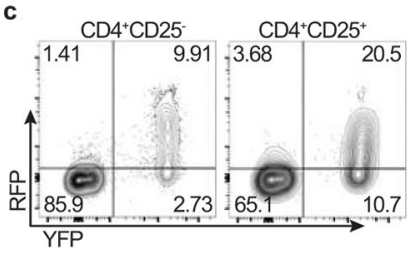
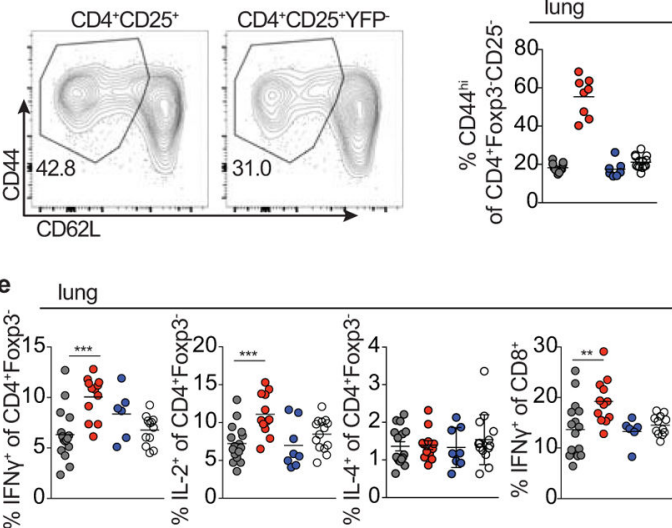
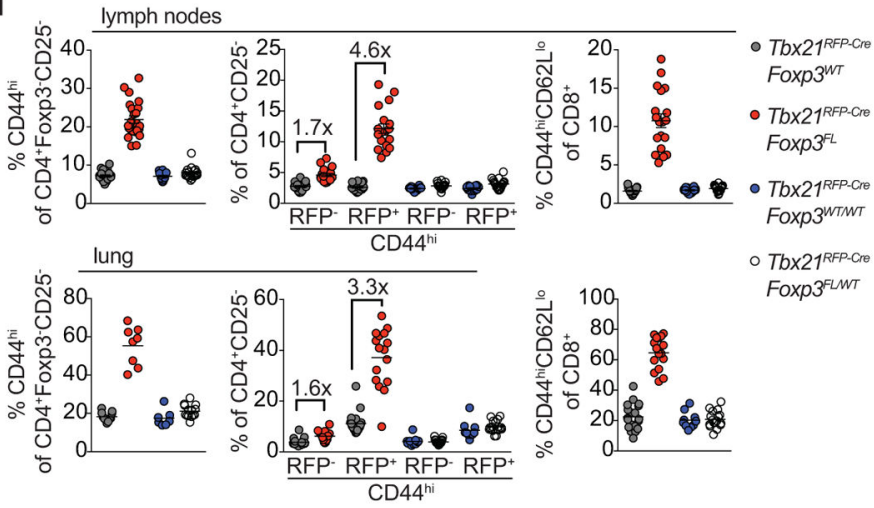

f

lymph nodes

TbX21 RFP-Cre

Foxp3 $3^{\text {LWT }}$

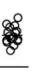

g

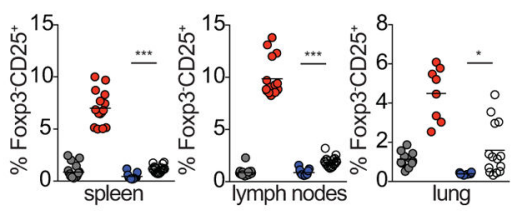

h Tbx21RF
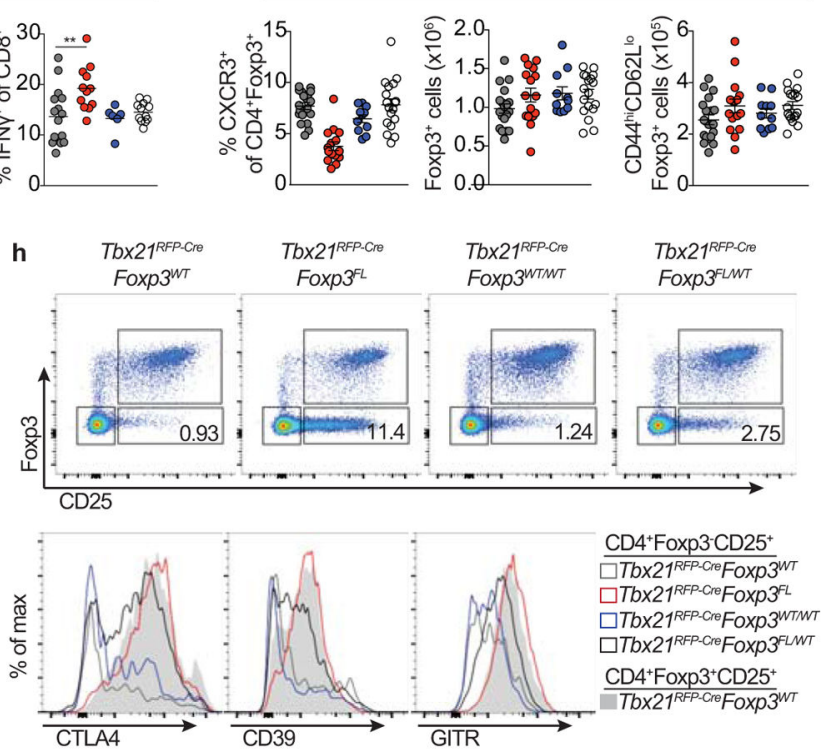

Extended Data Figure 6. The $\mathbf{T}_{\mathrm{H}} 2$ response to $N$. brasiliensis is not exacerbated in Tbx21 ${ }^{\text {RFP-Cre }}$ Foxp3 ${ }^{F L}$ mice

Tbx $21^{\text {RFP-Cre }}$ Foxp $3^{F L}$ and $T b \times 21^{R F P-C r e} F o x p 3^{W T}$ mice were infected with $N$. brasiliensis and analyzed on day 9 post challenge. a, Flow cytometry of GATA3 expression in $\mathrm{CD} 4^{+}{ }^{+} \mathrm{Foxp}^{-} \mathrm{CD} 25^{-} \mathrm{T}$ cells in spleens (above) and lungs (below) of Tbx $21^{R F P-C r e} \mathrm{Foxp} 3^{W T}$ (left) and $T b \times 21^{R F P-C r e} F o x p 3^{F L}$ (right) mice. b, Quantification of data in (a). c, Numbers of eosinophils in lungs of the indicated mice. $\mathbf{d}$, Cytokine production by $\mathrm{CD} 4^{+} \mathrm{Foxp} 3^{-}$and CD8 $\mathrm{T}$ cells in spleens and lungs of the indicated mice. Bars, mean \pm s.e.m. Two-tailed $t$ test (* 
denotes $p$ values $<0.05$; NS - not significant). Data represents 1 experiment, $\mathrm{n} \geq 5$ mice per group.

a

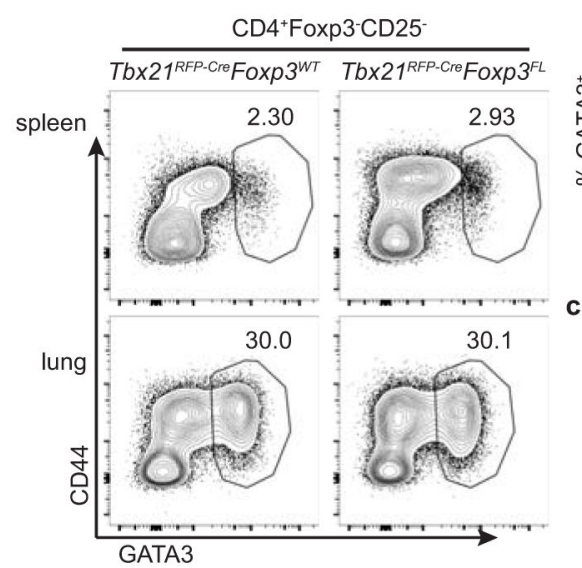

d
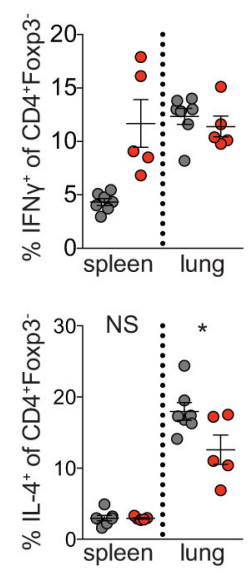
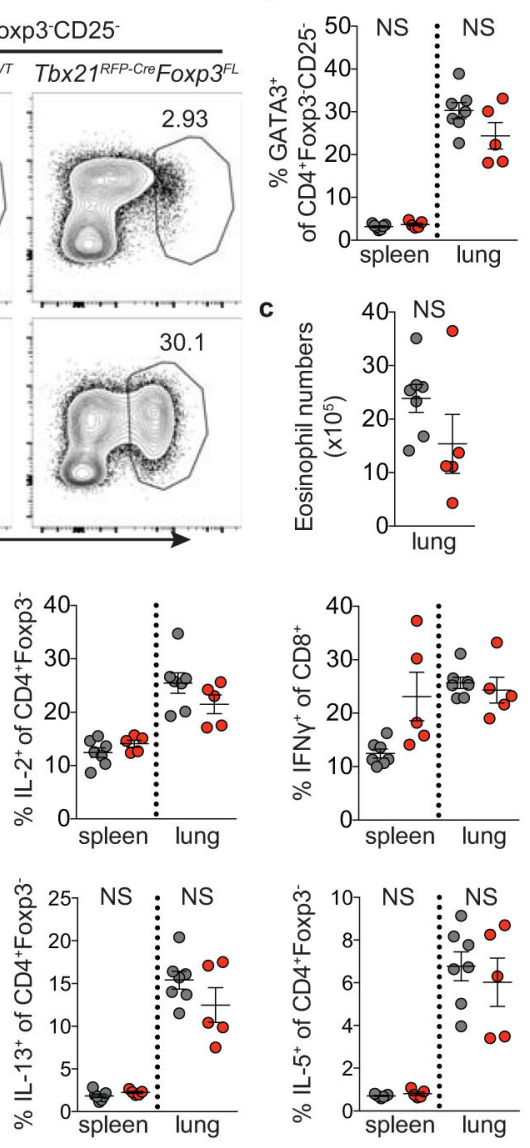

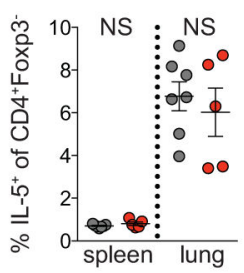

Extended Data Figure 7. Distinguishing the drivers of autoimmunity in the absence of T-bet ${ }^{+}$ Treg cells

a,b, ex-Treg cells are no more pathogenic than effector CD4 T cells. a, CD $4{ }^{+} \mathrm{CD} 25^{+}$(Treg) cells were sorted from lymph nodes of $\mathrm{Tb} \times 21^{\text {RFP-Cre }} \mathrm{Foxp} 3^{W T}$ mice, and $\mathrm{CD} 4^{+} \mathrm{CD} 25^{-}$ (effector) and $\mathrm{CD} 4^{+} \mathrm{CD} 25^{\text {lo }}$ (exTreg) cells were sorted from lymph nodes of Tbx $21^{\text {RFP-Cre } F o x p} 3^{F L}$ mice for transfer into $\mathrm{Tcrb}^{-/} \mathrm{Tcrd}^{-/}$mice. Intracellular staining for Foxp3 demonstrates purity of cell populations. b, Weights of $\mathrm{Tcrb}^{-/} \mathrm{Tcrd}^{-/}$mice receiving $\mathrm{CD} 4^{+} \mathrm{CD} 25^{+}$(white squares), $\mathrm{CD} 4^{+} \mathrm{CD} 25^{-}$(black squares), and $\mathrm{CD} 4^{+} \mathrm{CD} 25^{\text {lo }}$ (gray squares) cells. c, Percentages and numbers of the indicated $\mathrm{T}$ cell populations in spleens of mice analyzed on $\mathrm{d} 62$ post transfer. $\mathbf{d}, \mathbf{e}, \mathrm{T}^{- \text {bet }^{+}}$effector a $\beta \mathrm{T}$ cells drive disease upon ablation of T-bet ${ }^{+}$Treg cells. Lethally irradiated $T c r b^{-1} \mathrm{Tcrd}^{-/}$mice were reconstituted with a 1:1 mix of $C D 45.2^{+} T b \times 21^{R F P-C r e / W T} R 26^{i D T R}$ T-cell depleted bone marrow cells with either CD45.1 ${ }^{+}$Foxp $3^{K O}, C D 45.1^{+} F_{0 x p} 3^{W T}$, or $C D 45.2^{+} T_{c r b}{ }^{K O}$ T-cell depleted bone marrow cells. Mice were injected with $0.5 \mu \mathrm{g}$ diphtheria toxin (DT) on day 0 , then treated daily with $0.1 \mu \mathrm{g}$ DT for 22 days before analysis. d, Weight loss in $T b x 21^{R F P-C r e / W T} R 26^{i D T R}: F o x p 3^{K O}$ (red line) vs. Tbx $21^{R F P-C r e / W T} R 2 \sigma^{i D T R}: F o x p 3^{W T}$ (black line) vs. $T b \times 21^{R F P-C r e / W T} R 26^{i D T R}: T c r b^{K O}$ (blue line) reconstituted mice. e, Representative flow 
cytometry of splenic cell populations (indicated on right) in chimeric mice (as indicated above.) All data represent 1 experiment, $\mathrm{n} \geq 3$ mice per group.

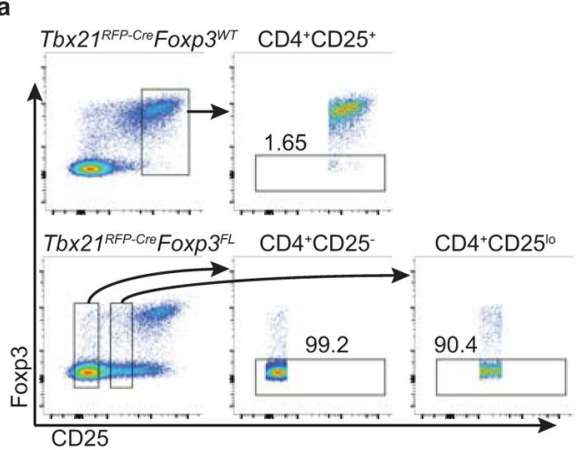

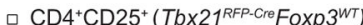

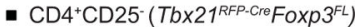

- $\mathrm{CD} 4^{+} \mathrm{CD} 25^{10}\left(\right.$ Tbx21 $1^{\text {RFP-Cre }}$ Foxp $\left.3^{F L}\right)$

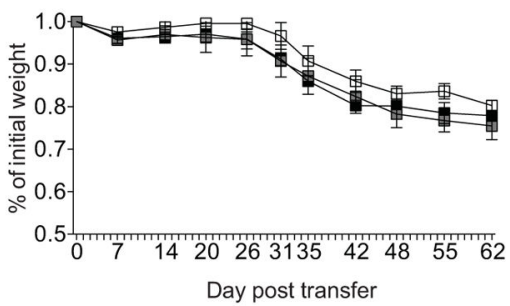

c
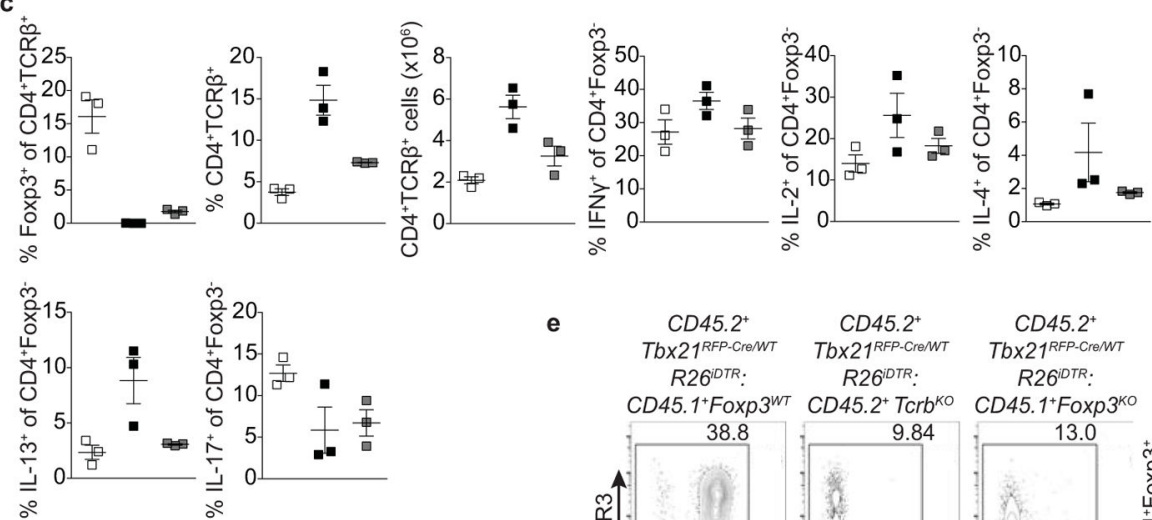

d

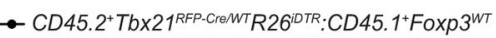

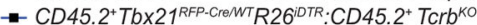

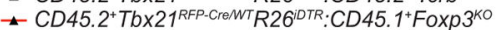

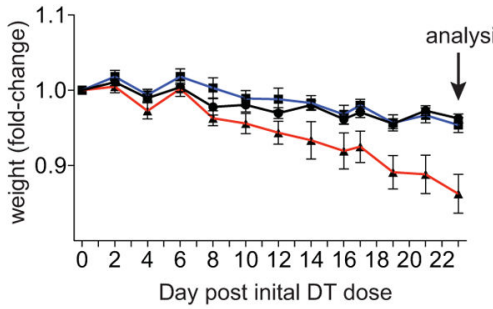

e

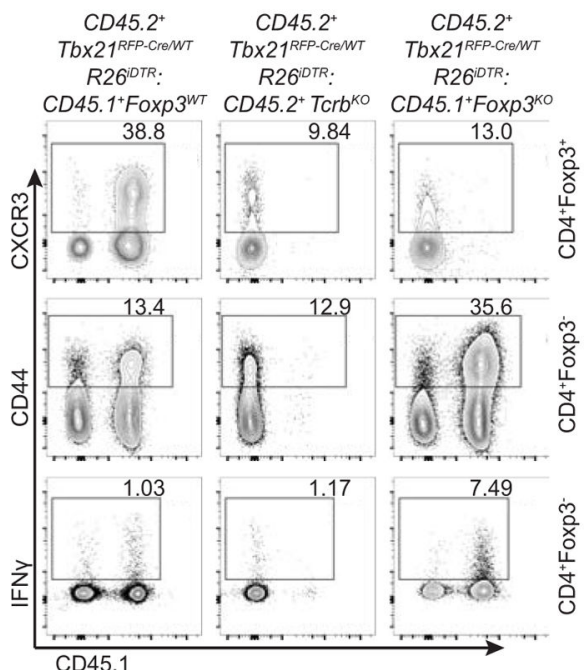

Extended Data Figure 8. Co-localization of T-bet ${ }^{+}$Treg and T-bet $^{+}$effector $\mathrm{T}$ cells in vivo a,b, Representative images (left) and insets (right) of lymph node sections from $T b \times 21^{R F P-C r e}$ mice with CD4 (a) or CD8 (b) in green, RFP in red, Foxp3 in blue, and CD44 in gray. In inset, arrowheads indicate $\mathrm{CD} 4{ }^{+} \mathrm{CD} 44^{\mathrm{hi}} \mathrm{RFP}^{+} \mathrm{Foxp}^{-}$(a) or $\mathrm{CD} 8{ }^{+} \mathrm{CD} 44^{\mathrm{hi}} \mathrm{RFP}^{+}$ (b) cells and arrows indicate $\mathrm{CD} 4{ }^{+} \mathrm{CD} 44^{\mathrm{hi}} \mathrm{RFP}^{+} \mathrm{Foxp} 3^{+}$cells. c,d, Quantification of nearest distances between Treg cells and CD4 (c) and CD8 (d) T cells, as shown in (a,b); Foxp3 ${ }^{+}$ denotes $\mathrm{CD}^{+}{ }^{+} \mathrm{CD} 44^{\text {hi }}{ }^{\mathrm{Foxp}} 3^{+}$; Foxp3 ${ }^{-}$(c) denotes CD $4^{+} \mathrm{CD} 44^{\mathrm{hi}}{ }_{\mathrm{Foxp}}{ }^{-}$and $\mathrm{CD}^{+}$(d) denotes $\mathrm{CD} 8^{+} \mathrm{CD} 44^{\mathrm{hi}} \mathrm{RFP}^{+}$. e,f, Quantification of nearest distances between Treg and nonTreg CD4 (e) and CD8 (f) $\mathrm{T}$ cells in spleens of $T b \times 21^{R F P-C r e F o x p} 3^{W T}$ and $T b \times 21^{R F P-} \mathrm{CreFoxp} 3^{F L}$ mice. Genotypes of mice are indicated above plots; cell types being analyzed are shown below plots, as in (c,d). Bars indicate mean. $p$ values were calculated 
using a two-tailed $t$ test $(\mathbf{c , d})$ or one-way ANOVA (e,f) $(* * *, * *$, and $*$ denotes $p$ values $<0.001,0.01$, and 0.05, respectively; NS - not significant). Data are representative of multiple imaged sections from $\geq 2$ mice.

a

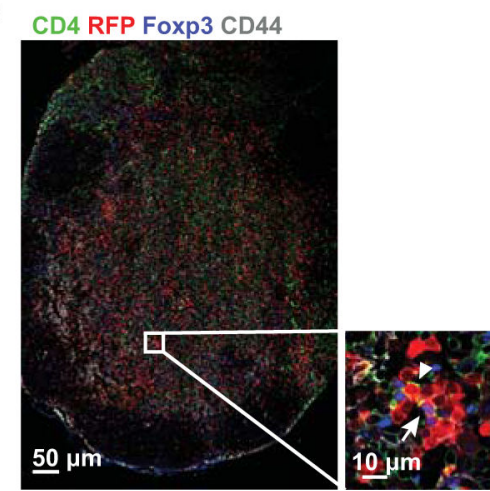

b

CD8 RFP Foxp3 CD44

c

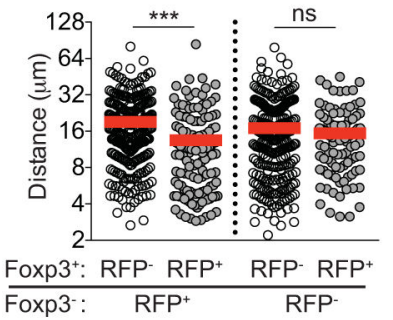

d
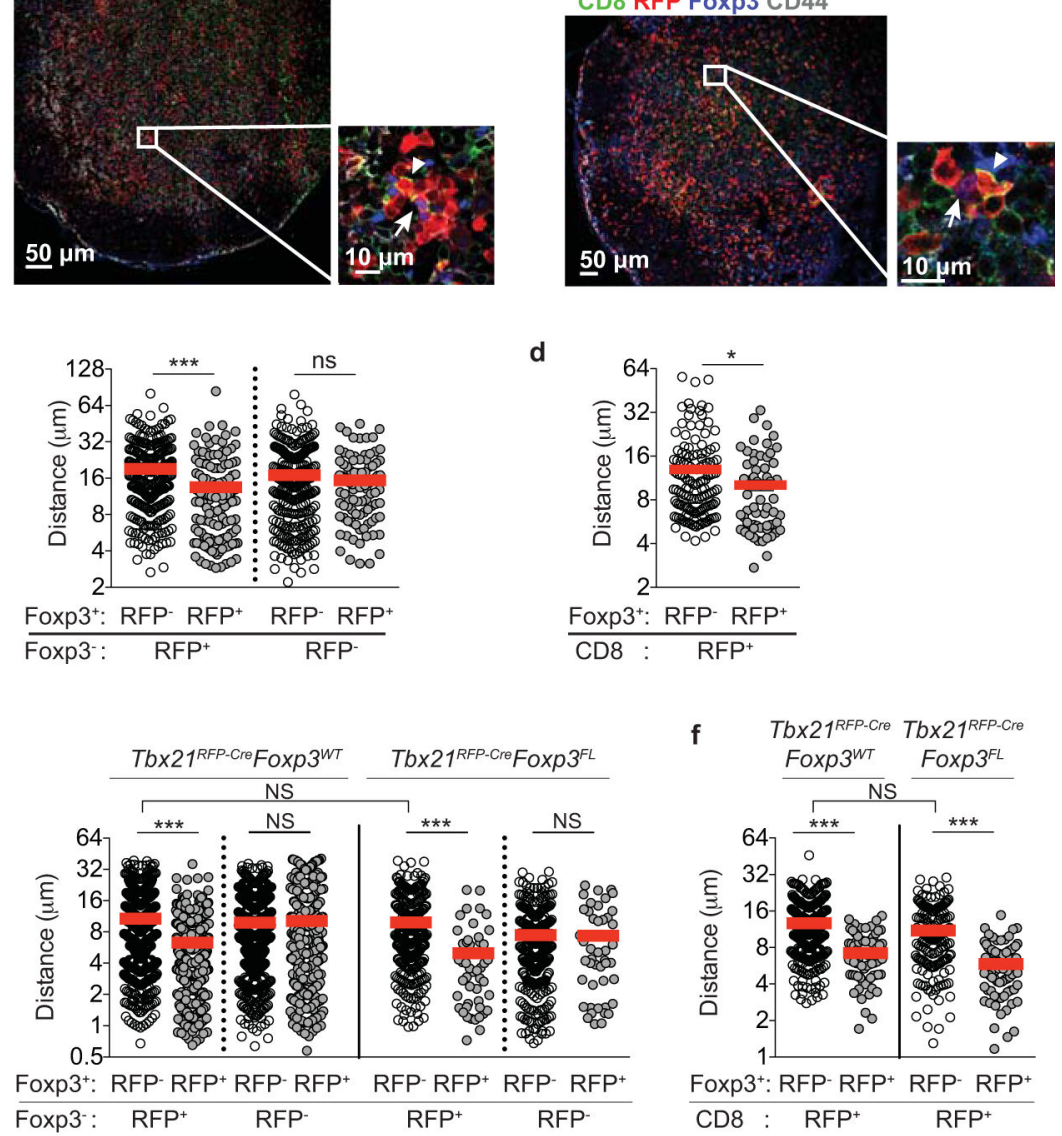

f Tb $21^{\text {RFP-Cre }}$ Tb $21^{\text {RFP-Cre }}$

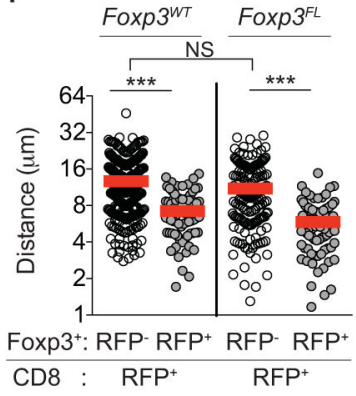

Extended Data Figure 9. T-bet ${ }^{+}$Treg cells suppress pre-established $T_{H} 1$ but not $T_{H} 2$ or $T_{H} 17$ activation induced by depletion of Treg cells

a, Targeting strategy for the Foxp3 locus. (b) Schematic for experiment shown in (c-g) depleting all Treg cells and subsequently depleting all or only non-T-bet-expressing Treg cells in Foxp $3^{f l-D T R e G F P} T b x 21^{R F P-C r e E R T 2}$ mice. c, Flow cytometry of splenic CD4 T cells in the indicated mice treated with tamoxifen (tx) or oil, as indicated. $\mathbf{d}-\mathbf{g}$, Percentages of Treg cells (d) and activation status of (e) and cytokine production by (f,g) splenic

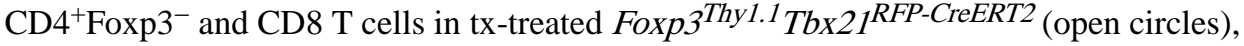
mock oil-treated Foxp $3^{f 1-D T R e G F P} T b \times 21^{R F P-C r e E R T 2}$ (black circles), and tx-treated Foxp $3^{f l-D T R e G F P} T b \times 21^{R F P-C r e E R T 2}$ (gray circles) mice. $\mathbf{h}-\mathbf{l}$, Treg cells rebounding post depletion in DT-treated Foxp $3^{D T R e G F P} T b \times 21^{R F P-C r e E R T 2}$ mice efficiently suppress $\mathrm{T}_{\mathrm{H}} 2$ responses. h, (left) Schematic for control experiment shown in (i-l); (right) flow cytometry of splenic CD4 T cells in mice treated with high dose DT (DT ${ }^{\text {hi }}, 1 \mu \mathrm{g} / \mathrm{mouse}$ ), low dose DT 
(DT ${ }^{\mathrm{lo}}, 0.0625 \mu \mathrm{g} / \mathrm{mouse}$ ), and PBS. Group 1 (control); group 2 (depletion without Treg cell recovery); group 3 (depletion with partial recovery); group 4 (depletion with full recovery). $\mathbf{i}-\mathbf{l}$, Percentages of Treg cells (i) and activation status of $(\mathbf{j})$ and cytokine production by $(\mathbf{k}, \mathbf{l})$ splenic $\mathrm{CD}^{+}{ }^{+} \mathrm{Foxp}^{-}{ }^{-}$and CD8 $\mathrm{T}$ cells in the indicated groups of mice. Bars, mean \pm s.e.m. Two-tailed $t$ test $(* * *, * *$, and $*$ denotes $p$ values $<0.001,0.01$, and 0.05 , respectively; NS not significant). Data are representative of $\geq 1$ experiment, $n \geq 4$ mice per group.
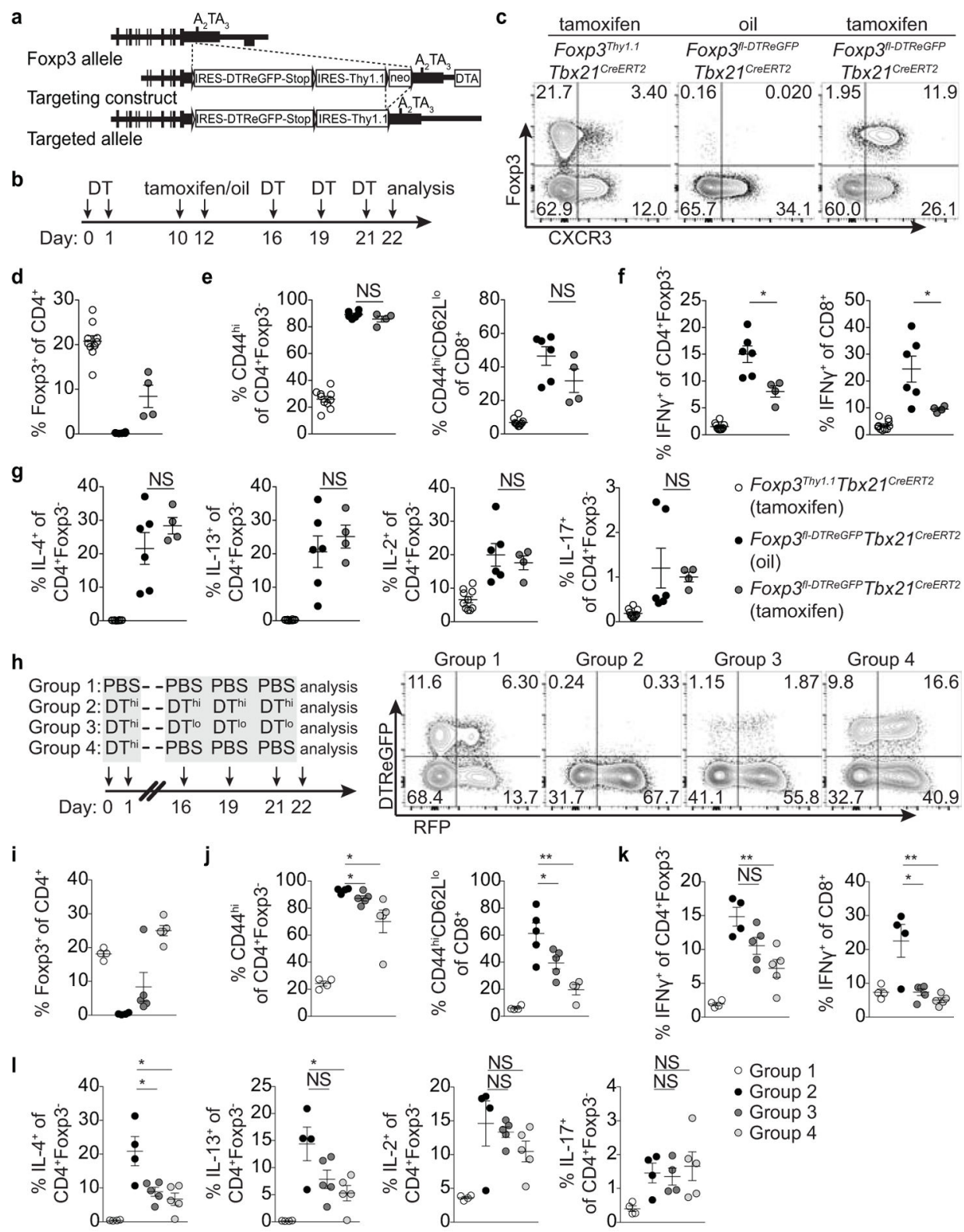

Extended Data Figure 10. Treg cells rebounding post transient depletion efficiently suppress $\mathbf{T}_{H^{2}} 2$ and $T_{H} 17$ responses

a, Experimental schematic. Mice were treated with tamoxifen (tx) or oil (to additionally control for potential effects of tx) on days -5 and -3 and received PBS on days $0,1,3,5,7$ (control); $1 \mu \mathrm{g}$ DT $\left(\mathrm{DT}^{\mathrm{hi}}\right.$ ) on days $0,1,3,5$, and 7 (no Treg cell recovery); 0.062 $\mu \mathrm{g}$ DT 
$\left(\mathrm{DT}^{\mathrm{lo}}\right.$ ) on days $0,1,3,5$, and 7 (partial Treg cell recovery); or $0.062 \mu \mathrm{g}$ DT $\left(\mathrm{DT}^{\mathrm{lo}}\right.$ ) on day 0 and PBS on days 1, 3, 5, and 7 (full Treg cell recovery). Mice were analyzed on day 9. b, Flow cytometry analysis of CD4 T cells in spleens of the indicated groups of mice. $\mathbf{c}-\mathbf{e}$, Percentages of Treg cells (c) and CD4 ${ }^{+} \mathrm{Foxp}^{-}$and CD8 $\mathrm{T}$ cell activation (d) and cytokine production (e) in spleens of the indicate mice (Group 1 - open circles; Group 2 - black circles; Group 3 - dark gray circles; Group 4 - light gray circles). Bars, mean \pm s.e.m. Twotailed $t$ test (*** and $* *$ denotes $p$ values $<0.001$ and 0.01 , respectively; NS - not significant). Data represent the combined results from 2 experiments, $n \geq 3$ mice per group.

\section{Supplementary Material}

Refer to Web version on PubMed Central for supplementary material.

\section{Acknowledgments}

We thank N. Arpaia, I. Leiner, and members of the Rudensky lab for discussions; J. Sun for providing Lm stocks; and A.H. Bravo, S.E. Lee, and M.B. Faire for experimental support. This work was supported by an NIH Medical Scientist Training Program grant T32GM07739 to the Weill Cornell/Rockefeller/Sloan-Kettering Tri-Institutional MD-PhD Program (A.G.L); the Frank Lappin Horsfall Jr. Student Fellowship (A.G.L); NIH grant R37AI034206 (A.Y.R.), the Ludwig Center at Memorial Sloan Kettering Cancer Center, and the Hilton-Ludwig Cancer Prevention Initiative (Conrad N. Hilton Foundation and Ludwig Cancer Research) (A.Y.R.); the NIH/NCI Cancer Center Support Grant P30 CA008748; the Russian Science Foundation project 14-14-00533 (E.V.P. and D.M.C) and the RFBR fellowship grant 16-34-60178 (E.V.P). A.Y.R. is an investigator with the Howard Hughes Medical Institute.

\section{References}

1. Zhu J, Yamane H, Paul WE. Differentiation of effector CD4 T cell populations (*). Annual review of immunology. 2010; 28:445-489.

2. Fontenot JD, Gavin MA, Rudensky AY. Foxp3 programs the development and function of CD4+CD25+ regulatory T cells. Nature immunology. 2003; 4:330-336. [PubMed: 12612578]

3. Hori S, Nomura T, Sakaguchi S. Control of regulatory T cell development by the transcription factor Foxp3. Science. 2003; 299:1057-1061. [PubMed: 12522256]

4. Koch MA, et al. The transcription factor T-bet controls regulatory $\mathrm{T}$ cell homeostasis and function during type 1 inflammation. Nature immunology. 2009; 10:595-602. [PubMed: 19412181]

5. Ohnmacht C, et al. MUCOSAL IMMUNOLOGY. The microbiota regulates type 2 immunity through RORgammat(+) T cells. Science. 2015; 349:989-993. [PubMed: 26160380]

6. Sefik E, et al. MUCOSAL IMMUNOLOGY. Individual intestinal symbionts induce a distinct population of RORgamma(+) regulatory T cells. Science. 2015; 349:993-997. [PubMed: 26272906]

7. Yu F, Sharma S, Edwards J, Feigenbaum L, Zhu J. Dynamic expression of transcription factors T-bet and GATA-3 by regulatory T cells maintains immunotolerance. Nature immunology. 2015; 16:197206. [PubMed: 25501630]

8. Zhou L, et al. TGF-beta-induced Foxp3 inhibits T(H)17 cell differentiation by antagonizing RORgammat function. Nature. 2008; 453:236-240. [PubMed: 18368049]

9. Hwang ES, Szabo SJ, Schwartzberg PL, Glimcher LH. T helper cell fate specified by kinasemediated interaction of T-bet with GATA-3. Science. 2005; 307:430-433. [PubMed: 15662016]

10. Koch MA, et al. T-bet(+) Treg cells undergo abortive Th1 cell differentiation due to impaired expression of IL-12 receptor beta2. Immunity. 2012; 37:501-510. [PubMed: 22960221]

11. Laidlaw BJ, et al. Production of IL-10 by CD4(+) regulatory T cells during the resolution of infection promotes the maturation of memory CD8(+) T cells. Nature immunology. 2015; 16:871879. [PubMed: 26147684]

12. Colbeck EJ, et al. Eliminating roles for T-bet and IL-2 but revealing superior activation and proliferation as mechanisms underpinning dominance of regulatory $\mathrm{T}$ cells in tumors. Oncotarget. 2015; 6:24649-24659. [PubMed: 26433463] 
13. McPherson RC, Turner DG, Mair I, O’Connor RA, Anderton SM. T-bet Expression by Foxp3(+) T Regulatory Cells is Not Essential for Their Suppressive Function in CNS Autoimmune Disease or Colitis. Frontiers in immunology. 2015; 6:69. [PubMed: 25741342]

14. Williams LM, Rudensky AY. Maintenance of the Foxp3-dependent developmental program in mature regulatory T cells requires continued expression of Foxp3. Nature immunology. 2007; 8:277-284. [PubMed: 17220892]

15. Smith KA, et al. Low-level regulatory T-cell activity is essential for functional type- 2 effector immunity to expel gastrointestinal helminths. Mucosal immunology. 2016; 9:428-443. [PubMed: 26286232]

16. Sawant DV, et al. Regulatory T cells limit induction of protective immunity and promote immune pathology following intestinal helminth infection. Journal of immunology. 2014; 192:2904-2912.

17. Lahl K, et al. Nonfunctional regulatory $\mathrm{T}$ cells and defective control of Th2 cytokine production in natural scurfy mutant mice. Journal of immunology. 2009; 183:5662-5672.

18. Lin W, et al. Regulatory $\mathrm{T}$ cell development in the absence of functional Foxp3. Nature immunology. 2007; 8:359-368. [PubMed: 17273171]

19. Liu Z, et al. Immune homeostasis enforced by co-localized effector and regulatory T cells. Nature. 2015; 528:225-230. [PubMed: 26605524]

20. Intlekofer AM, et al. Anomalous type 17 response to viral infection by CD8+ T cells lacking T-bet and eomesodermin. Science. 2008; 321:408-411. [PubMed: 18635804]

21. Liston A, et al. Differentiation of regulatory Foxp3+ T cells in the thymic cortex. Proceedings of the National Academy of Sciences of the United States of America. 2008; 105:11903-11908. [PubMed: 18695219]

22. Rubtsov YP, et al. Regulatory T cell-derived interleukin-10 limits inflammation at environmental interfaces. Immunity. 2008; 28:546-558. [PubMed: 18387831]

23. Srinivas $\mathrm{S}$, et al. Cre reporter strains produced by targeted insertion of EYFP and ECFP into the ROSA26 locus. BMC developmental biology. 2001; 1:4. [PubMed: 11299042]

24. Eberl G, et al. An essential function for the nuclear receptor RORgamma(t) in the generation of fetal lymphoid tissue inducer cells. Nature immunology. 2004; 5:64-73. [PubMed: 14691482]

25. Kamanaka M, et al. Expression of interleukin-10 in intestinal lymphocytes detected by an interleukin-10 reporter knockin tiger mouse. Immunity. 2006; 25:941-952. [PubMed: 17137799]

26. Buch T, et al. A Cre-inducible diphtheria toxin receptor mediates cell lineage ablation after toxin administration. Nature methods. 2005; 2:419-426. [PubMed: 15908920]

27. Camberis M, Le Gros G, Urban J Jr. Animal model of Nippostrongylus brasiliensis and Heligmosomoides polygyrus. Current protocols in immunology/edited by John E. Coligan ... [et al.]. 2003; Chapter 19(Unit 19):12.

28. Li H, Durbin R. Fast and accurate long-read alignment with Burrows-Wheeler transform. Bioinformatics. 2010; 26:589-595. [PubMed: 20080505]

29. McKenna A, et al. The Genome Analysis Toolkit: a MapReduce framework for analyzing nextgeneration DNA sequencing data. Genome research. 2010; 20:1297-1303. [PubMed: 20644199]

30. Love MI, Huber W, Anders S. Moderated estimation of fold change and dispersion for RNA-seq data with DESeq2. Genome biology. 2014; 15:550. [PubMed: 25516281]

31. Feng Y, et al. A mechanism for expansion of regulatory T-cell repertoire and its role in selftolerance. Nature. 2015; 528:132-136. [PubMed: 26605529] 
a

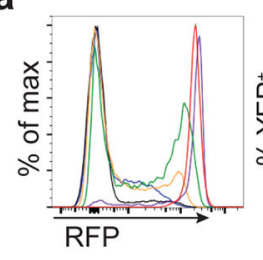

b

Day: -20
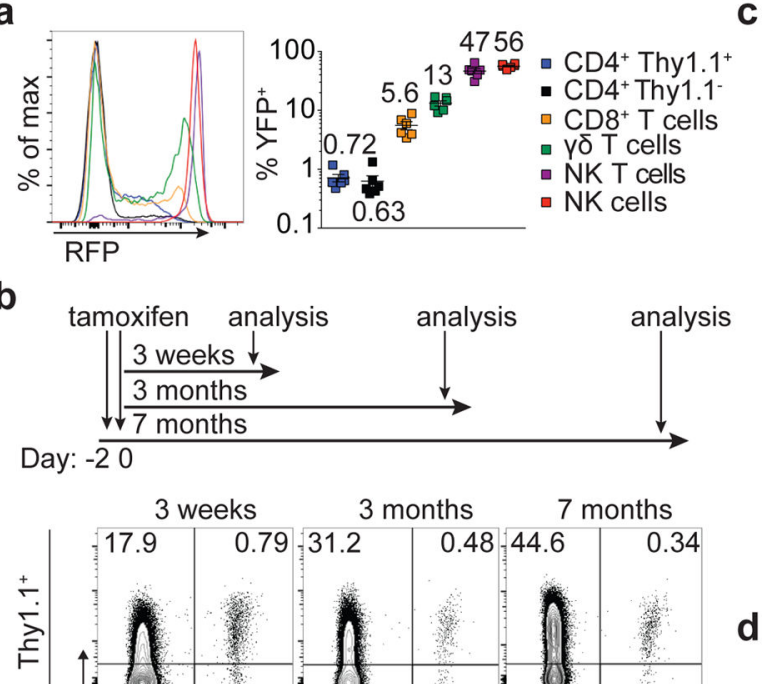
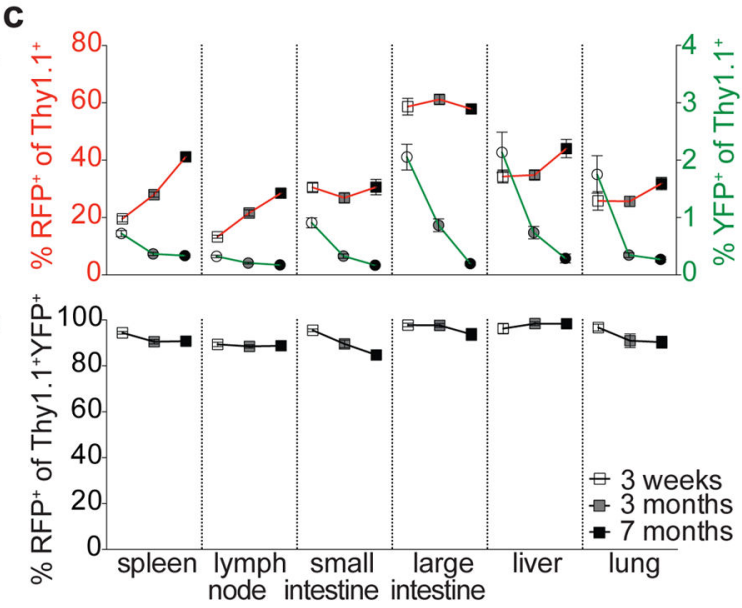

d tamoxifen $\mathrm{Nb}$ or PBS analysis $\square$ Thy $1.1^{+}$(PBS)

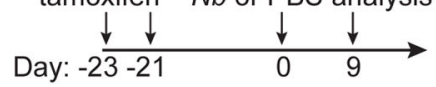
$\square$ Thy $1.1^{+}(\mathrm{Nb})$

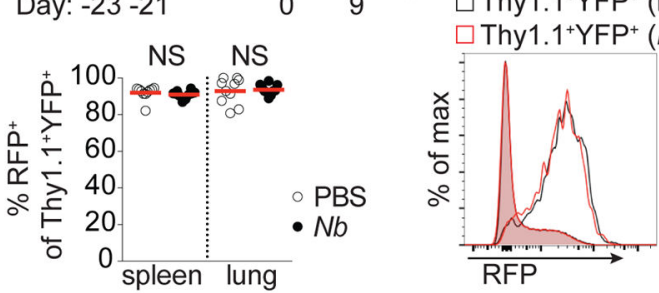

Figure 1. Stable T-bet expression in a subset of peripheral Treg cells

a, Splenic cells in $T b \times 21^{R F P-C r e E R T 2}$ mice 3 weeks following tamoxifen (tx) gavage on days -2 and 0 . Numbers on graph (right) indicate the mean. $\mathbf{b}$, Schematic of tx administration to $T b \times 21^{R F P-C r e E R T 2}$ mice (above) and flow cytometry (below) of splenic CD4 Thy $1.1^{+}$and Thy $1.1^{-}$cells. c, (Above) $\mathrm{RFP}^{+}$(left axis, squares) and $\mathrm{YFP}^{+}$(right axis, circles) Treg cells; (below) Percent $\mathrm{RFP}^{+}$of $\mathrm{YFP}^{+}$Treg cells 3 weeks (white symbols), 3 months (gray symbols), and 7 months (black symbols) post tx gavage. d, (Above) schematic of tx treatment with Nippostrongylus brasiliensis $(\mathrm{Nb})$ infection; (below, left) percent $\mathrm{RFP}^{+}$ among $\mathrm{YFP}^{+}$Treg cells in PBS- (white circles) and $N b$ - (black circles) challenged mice; (below, right) RFP expression in Treg (shaded histograms) or $\mathrm{YFP}^{+}$Treg (open histograms) cells from spleens of PBS- (black) or $\mathrm{Nb}$ - (red) challenged mice. Bars, mean \pm s.e.m. Twotailed $t$ test (NS - not significant). All data are representative of 2 experiments, $\mathrm{n} \geq 3$ mice per group each. 
a

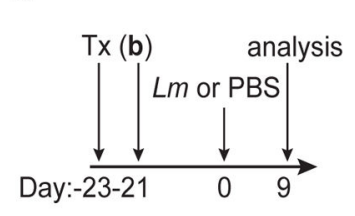

C

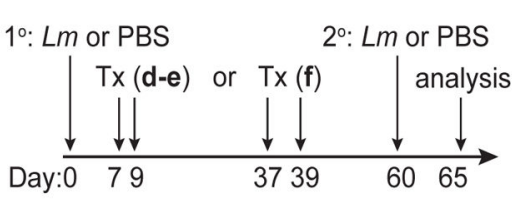

e +100

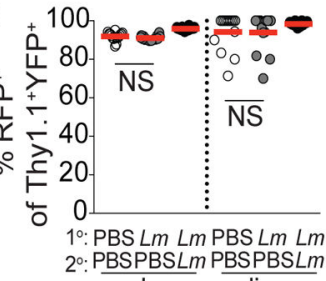

spleen $\frac{\text { liver }}{2}$

b
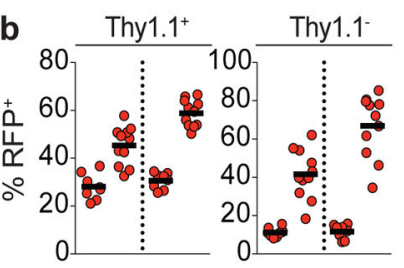

d $80 \frac{\text { Thy } 1.1^{+}}{1.4 x \vdots 1.6 x}$

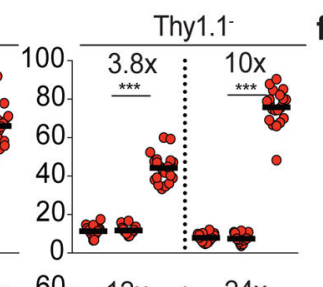

$f$

f

$1 0 0 \longdiv { 1 . 6 \mathrm { x } : 1 . 6 \mathrm { x } }$
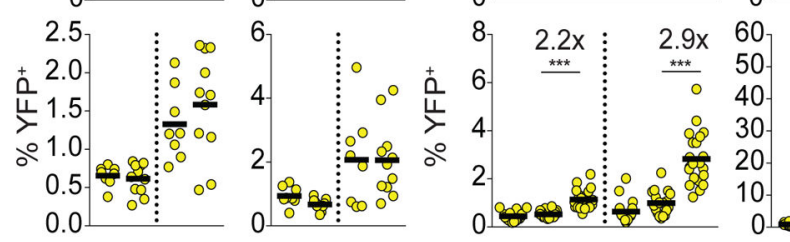

\begin{tabular}{r}
$12 x$ \\
\hdashline$* x$ \\
0 \\
0 \\
0 \\
0 \\
0 \\
8 \\
8
\end{tabular}
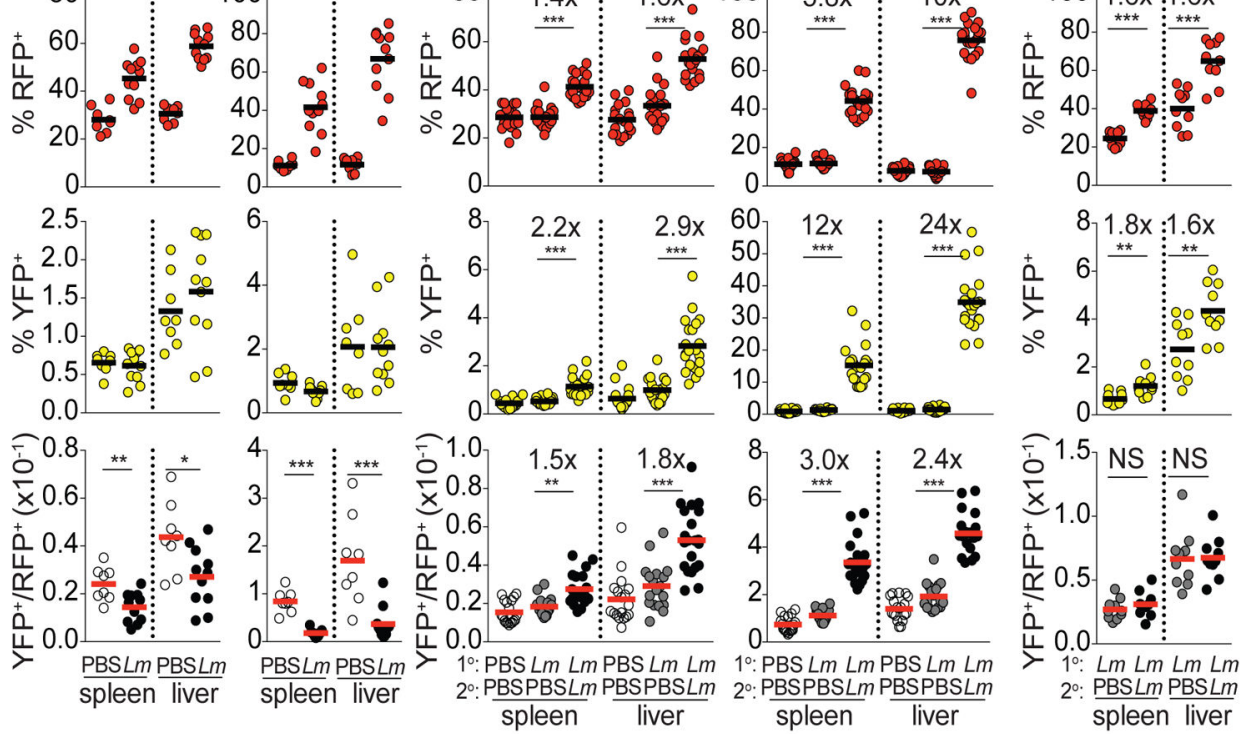

Figure 2. Stable differentiation of T-bet ${ }^{+}$Treg cells in response to $L$. monocytogenes infection a, Schematic of experiment shown in (b) combining tamoxifen (tx) treatment with $\mathrm{Lm}$ infection in $T b \times 21^{R F P-C r E E R T 2}$ mice. b, Percent $\mathrm{RFP}^{+}, \mathrm{YFP}^{+}$, and $\mathrm{YFP}^{+} / \mathrm{RFP}^{+}$ratio in $\mathrm{CD}^{+}$ Thy $1.1^{+}$(left) and Thy 1.1- (right) cells in spleens and livers of PBS and Lm challenged mice. c, Schematic of experiments shown in (d,e) and (f); $1^{\circ}$ and $2^{\circ}$ indicate primary and secondary challenge, respectively. d, data presented as in (b). e, Percent $\mathrm{RFP}^{+}$of $\mathrm{YFP}^{+}$Treg cells. f, data presented as in (b). Bars, mean. Two-tailed $t$ test $(* * *, * *$, and $*$ denotes $p$ values $<0.001,0.01$, and 0.05 , respectively; NS - not significant). All data are representative of $\geq 2$ experiments, $n \geq 4$ mice per group each.

Nature. Author manuscript; available in PMC 2017 December 07. 
a

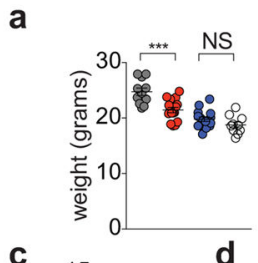

b
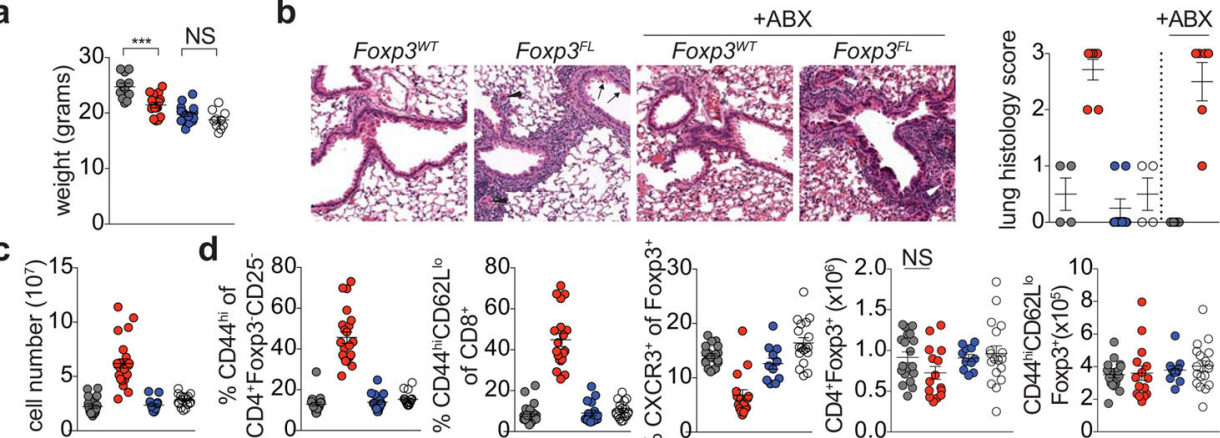

d

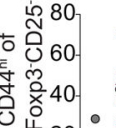

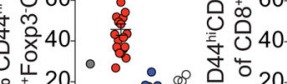

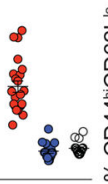

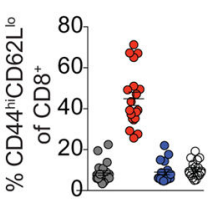

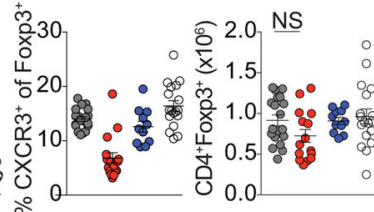

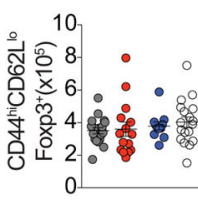

e
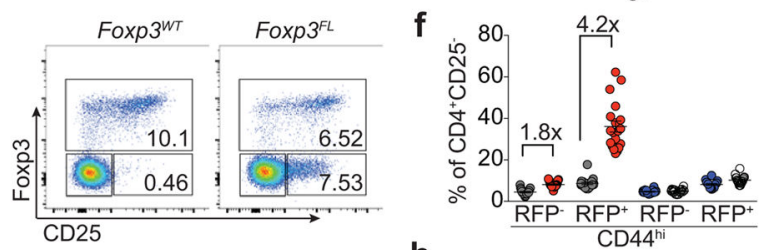

g
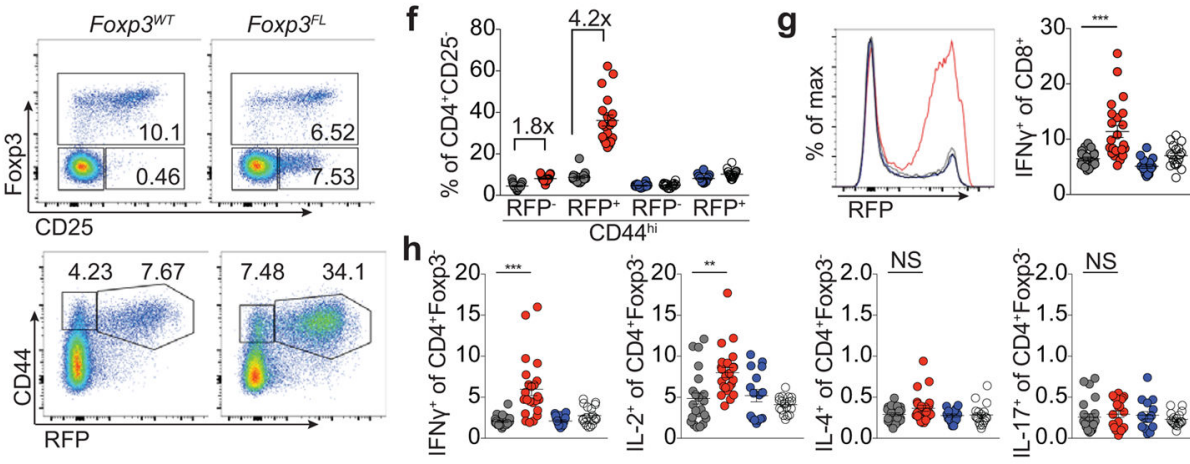

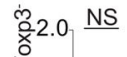
证 1.5 记 1.0 01.0

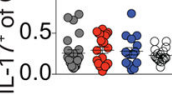

i
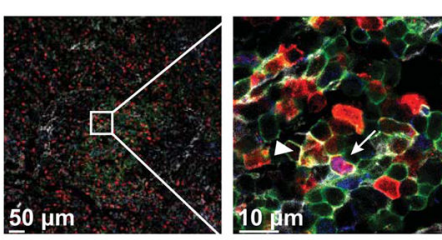

j

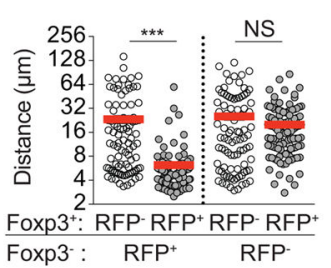

k
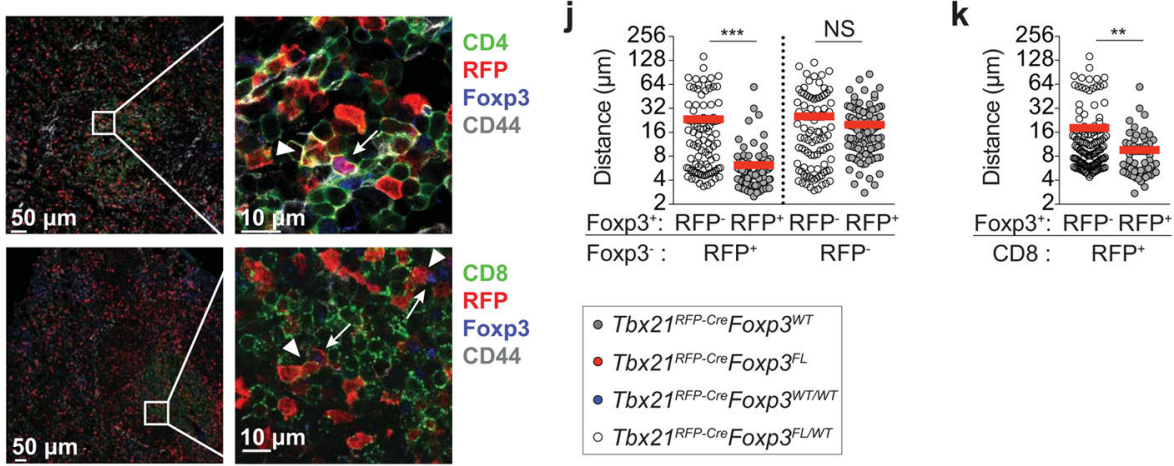

CD8

RFP
Foxp3

- Tbx21 $1^{\text {RP-Cro }} F o x p 3^{W T}$

- Tbx21 ${ }^{\text {RFP-Cre }}$ Foxp $3^{\text {FL }}$

- Tbx21 RFP-Cre Foxp $3^{\text {WTNT }}$

- Tbx $21^{\text {RFP-Cre Foxp }} 3^{\text {FLWT }}$

Figure 3. Foxp3 ablation in T-bet ${ }^{+}$Treg cells results in spontaneous $\mathbf{T}_{\mathbf{H}} \mathbf{1}$ autoimmune disease a, Body weights of 8-10 wk old $T b \times 21^{R F P-C r e} F o x p 3^{W T}$ (gray circles),

$T b \times 21^{R F P-C r e} F o x p 3^{F L}$ (red circles), Tbx $21^{R F P-C r e} F o x p 3^{W T / W T}$ (blue circles), and

$T b \times 21^{R F P-C r e} F o x p 3^{F L / W T}$ (white circles) mice. b, H\&E staining (left) and histology scores (right) of lungs from $T b \times 21^{R F P-C r e}$ mice combined with indicated Foxp3 alleles, treated or not with antibiotics $(\mathrm{ABX}) . T b \times 21^{R F P-C r e} F o x p 3^{F L}$ mice show moderate perivascular and peribronchiolar inflammation, mild respiratory epithelial hyperplasia and mucus metaplasia with hyalinization (arrows). Pulmonary arterioles are contracted with thickened media, reactive endothelia, and marginating leukocytes (arrowheads). Original magnification, 20x. c, Lymph node cell numbers and $\mathbf{d}$, characterization of $\mathrm{T}$ cell populations in spleens. e, Flow cytometry of splenic cells in $T b \times 21^{R F P-C r} F o x p 3^{W T}$ (left) and $T b \times 21^{R F P-C r e} F o x p 3^{F L}$ (right) mice, gated on fixed $\mathrm{CD}^{+}$(above) and live $\mathrm{CD} 4{ }^{+} \mathrm{CD} 25^{-}$(below) cells. f, Quantification of $\mathrm{RFP}^{-}$and $\mathrm{RFP}^{+}$CD4 T cells, as shown in (e, bottom). $\mathbf{g}$, RFP expression (left) and cytokine production (right) in splenic CD8 T cells. h, Cytokine production by splenic CD $4^{+} \mathrm{Foxp}^{-} \mathrm{T}$ cells. i, Representative images (left) and insets (right) of spleen sections from $T b \times 21^{R F P-C r e}$ 
mice with CD4 (green, above) or CD8 (green, below), RFP (red), Foxp3 (blue), CD44 (gray). Inset, arrowheads indicate $\mathrm{CD} 4{ }^{+} \mathrm{CD} 444^{\mathrm{hi}} \mathrm{RFP}^{+} \mathrm{Foxp}^{-}$(above) or $\mathrm{CD} 8{ }^{+} \mathrm{CD} 44^{\mathrm{hi}} \mathrm{RFP}^{+}$ (below) cells and arrows indicate $\mathrm{CD} 4{ }^{+} \mathrm{CD} 44^{\mathrm{hi}} \mathrm{RFP}^{+} \mathrm{Foxp} 3^{+}$cells. $\mathbf{j}-\mathbf{k}$, Nearest distances between cells as shown in (i); Foxp3 ${ }^{+}$denotes $\mathrm{CD} 4^{+} \mathrm{CD} 44^{\text {hi }} \mathrm{Foxp}^{+}$; Foxp3 $3^{-}$(j) denotes $\mathrm{CD} 4{ }^{+} \mathrm{CD} 44^{\text {hi }}{ }^{\mathrm{Foxp}} 3^{-}$and $\mathrm{CD} 8^{+}(\mathbf{k})$ denotes $\mathrm{CD} 8{ }^{+} \mathrm{CD} 44^{\mathrm{hi}} \mathrm{RFP}^{+}$. Each circle $(\mathbf{j}, \mathbf{k})$ represents the distance between cells on imaged sections from three mice. Bars, mean \pm s.e.m. Twotailed $t$ test (*** and $* *$ denotes $p$ values $<0.001$ and 0.01 , respectively; NS - not significant). All data are representative of several experiments. 
a

$\ominus C D 45.2^{+}$Tbx $21^{\text {RFP-CreNT }} R 26^{\text {IDTR: }}$
CD $45.1^{+}$Foxp $3^{W T}$ (control)

- CD45.2+Tbx21 RFP-CreNTT2 $26^{\text {IDTR: }}$ CD45.1 ${ }^{+}$Foxp $^{K O}$ (T-bet ${ }^{+}$depleted)

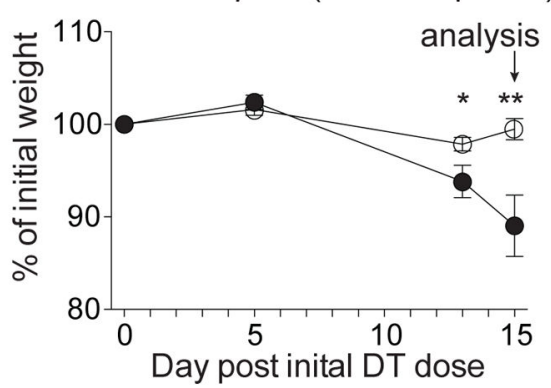

b

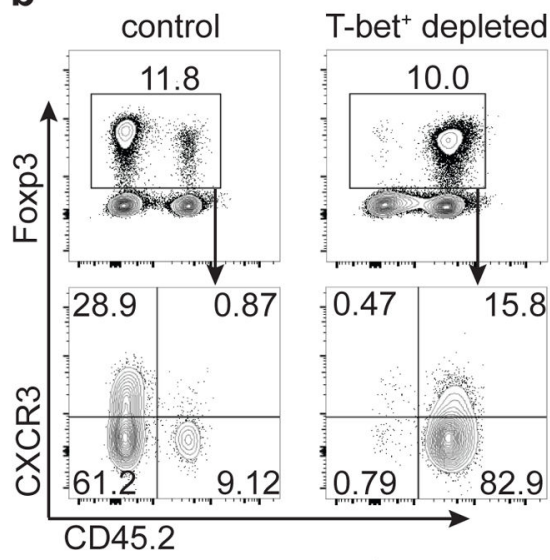

$$
d^{d}
$$
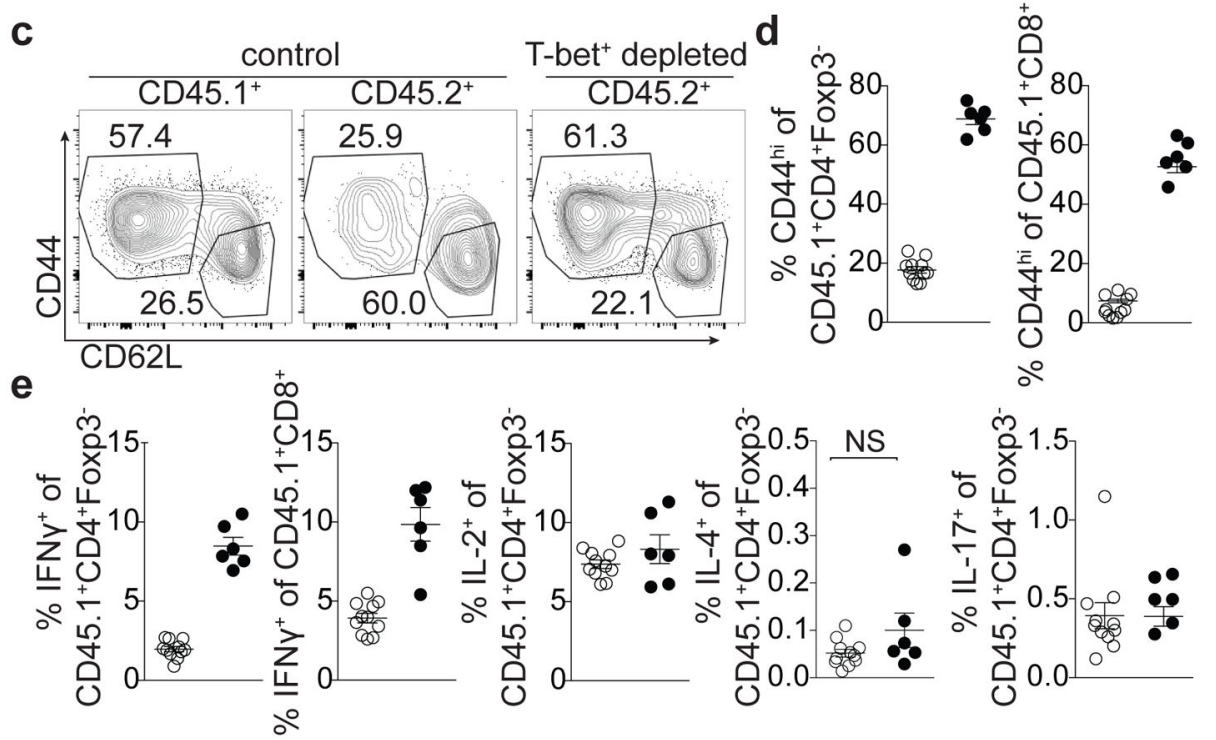

Figure 4. Acute ablation of T-bet ${ }^{+}$Treg cells results in $T_{H} \mathbf{1}$ immune activation Bone marrow chimeric mice were injected with $0.5 \mu \mathrm{g}$ diphtheria toxin (DT) on d0, then treated daily with $0.1 \mu \mathrm{g}$ DT until d15. a, Weight loss in the indicated mice. b. Flow cytometry of splenic CD4 (above) and Treg (below) cells in the indicated mice. c, Activation status of CD45.1 $1^{+}$and CD45.2 $2^{+}$Treg cell compartments in spleens of indicated mice. d,e, T cell activation (d) and cytokine production (e) in control (white circles) and T-bet Treg depleted (black circles) chimeras. Bars, mean \pm s.e.m. Two-tailed $t$ test (** and $*$ denotes $p$ values $<0.01$ and 0.05 , respectively; NS - not significant). Data is representative of 2 experiments, $\mathrm{n} \geq 6$ mice per group. 
a

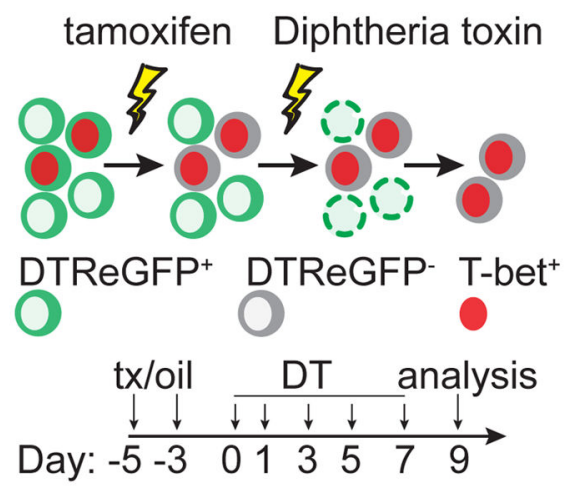

C

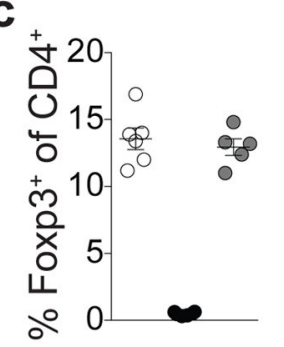

d

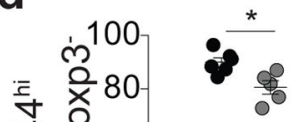

f b

\begin{tabular}{ccc} 
tamoxifen & oil & tamoxifen \\
\hline Foxp3 & Thy1.1 & Foxp3 \\
fl-DTREGFP & Foxp3 $3^{\text {fl-DTReGFP }}$
\end{tabular}

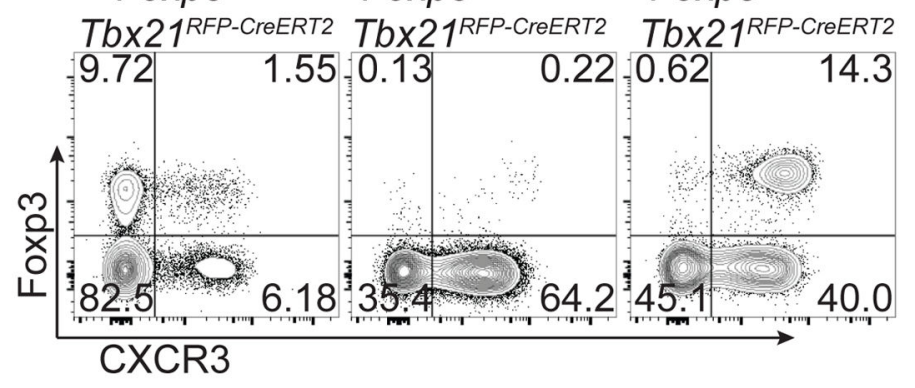

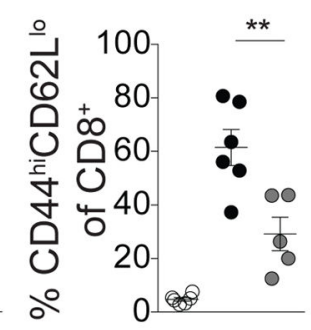

e
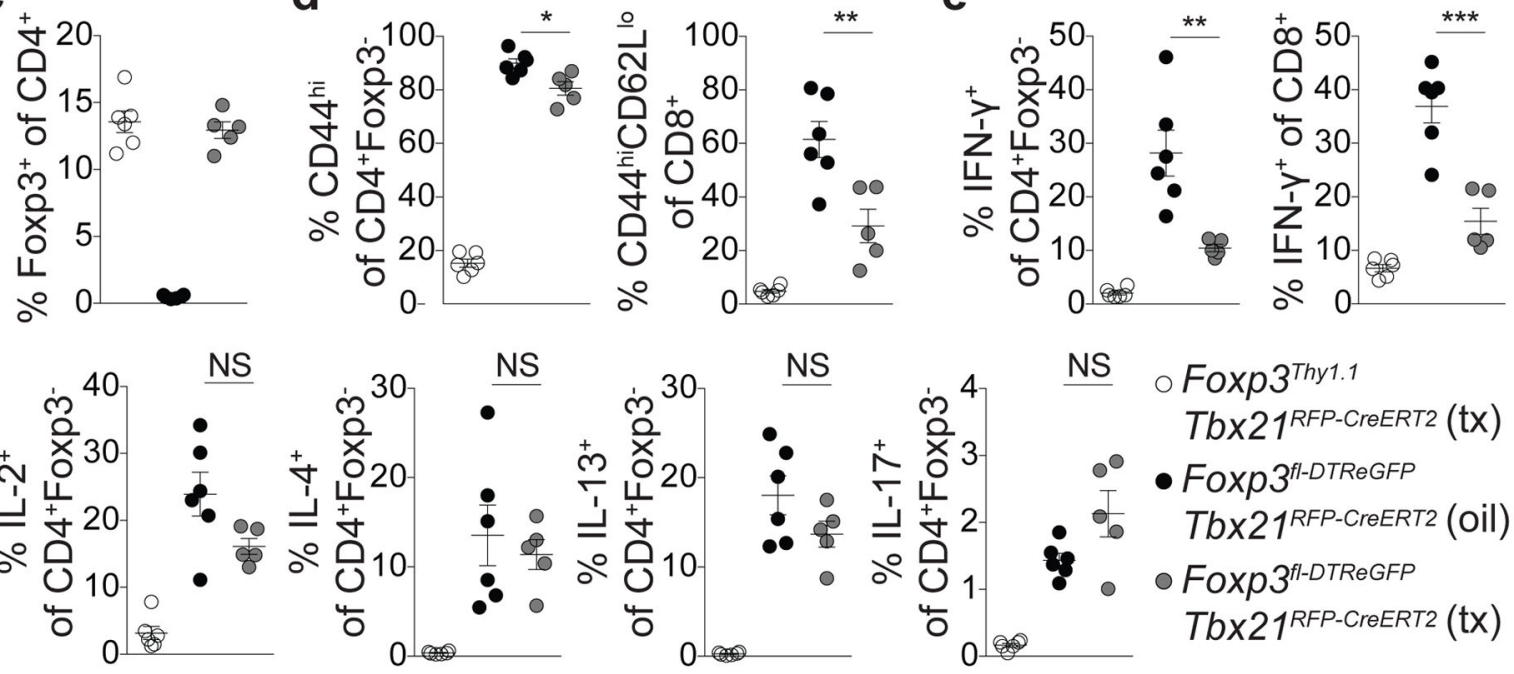

Figure 5. $T$-bet ${ }^{+}$Treg cells suppress $T_{H} 1$ and $C_{D 8}{ }^{+} T$ cell but not $T_{H} 2$ or $T_{H} 17$ responses a, Schematic for tamoxifen (tx) administration and depletion of non-T-bet-expressing Treg cells in Foxp $3^{f l-D T R e G F P} T b \times 21^{R F P-C r e E R T 2}$ mice. b, Flow cytometry of splenic CD4 T cells in the indicated mice on $\mathrm{d} 9$, as outlined in (a). c-f, Treg cell percentages (c), and activated (d) and cytokine producing (e,f) T cells in spleens of tx-treated Foxp3 $3^{\text {Thy } 1.1}$ Tbx $21^{\text {RFP-CreERT2 }}$ (open circles), oil-treated Foxp $3^{\text {fl-DTReGFP } T b \times 21^{R F P-C r e E R T 2}}$ mice (black circles) and tx-treated Foxp $3^{f 1-D T R e G F P} T b \times 21^{R F P-C r e E R T 2}$ mice (gray circles) mice. Bars, mean \pm s.e.m. Two-tailed $t$ test $(* * *, * *$, and $*$ denotes $p$ values $<0.001,0.01$, and 0.05 , respectively; NS - not significant). Data are representative of 2 experiments, $n \geq 3$ mice per group each. 